\title{
The Role of Spray-Enhanced Swirl Flow for Combustion Stabilization in a Stratified- Charge DISI Engine
}

\author{
Wei Zeng ${ }^{\mathrm{a}}$, Magnus Sjöberg ${ }^{\mathrm{a}}$, David L. Reuss ${ }^{\mathrm{a}, \mathrm{b}}$, Zongjie $\mathrm{Hu}^{\mathrm{c}}$ \\ a Sandia National Laboratories, MS 9053, PO Box 969, Livermore, CA 94551-0969, USA \\ b University of Michigan, 1231 Beal Ave., Ann Arbor, MI, 48109, USA \\ c Tongji University, 1239 Siping Rd., Shanghai, 200092, China \\ Email address for contact person: wei.g.zeng@gmail.com (Wei Zeng)
}

\begin{abstract}
Implementation of spray-guided stratified-charge direct-injection spark-ignited (DISI) engines is inhibited by the occurrence of misfire and partial burns. Engine-performance tests demonstrate that increasing engine speed induces combustion instability, but this deterioration can be prevented by generating swirling flow during the intake stroke. In-cylinder pressure-based heat-release analysis reveals that the appearance of poor-burn cycles is not solely dependent on the variability of early flame-kernel growth. Cycles can experience burning-rate regression during later combustion stages and may or may not recover before the end of the cycle. Thermodynamic analysis and optical diagnostics are used here to clarify why swirl improves the combustion repeatability from cycle to cycle.

The fluid dynamics of swirl/spray interaction was previously demonstrated using high-speed PIV measurements of in-cylinder motored flow. It was found that the sprays of the multi-hole injector redistribute the intake-generated swirl flow momentum, thereby creating a better-centered higher angularmomentum vortex with reduced variability. The engine operation with high swirl was found to have significant improvement in cycle-to-cycle variations of both flow pattern and flow momentum.

This paper is an extension of the previous work. Here, PIV measurements and flame imaging are applied to fired operation for studying how the swirl flow affects variability of ignition and subsequent combustion phases. PIV results for fired operation are consistent with the measurements made of motored flow. They demonstrate that the spark-plasma motion is highly correlated with the direction of the gas flow in the vicinity of the spark-plug gap. Without swirl, the plasma is randomly stretched towards either side of the spark plug, causing variability in the ignition of the two spray plumes that are straddling the spark plug. In contrast, swirl flow always convects the spark plasma towards one spray plume, causing a more repeatable ignition. The swirl decreases local RMS velocity, consistent with an observed reduction of early-burn variability. Broadband flame imaging demonstrates that with swirl, the flame consistently propagates in multiple directions to consume fuel-air mixtures within the piston bowl. In contrast, operation without swirl displays higher variability of flame-spread patterns, occasionally causing the appearance of partial-burn cycles.
\end{abstract}

Key words: Spray-guided stratified-charge DISI engine, Combustion stabilization, Swirl flow and swirlspray interaction, Flame propagation, High-speed PIV and flame natural luminosity imaging. 


\section{Introduction}

High thermal efficiency is achievable for spark-ignited direct-injection (SIDI) engines using unthrottled stratified-charge (SC) combustion [1]. The attraction of increased fuel efficiency has resulted in efforts to bring SC DISI engines into production $[2,3]$. Spray-guided (SG) SC engines with improved fuel economy reached production in Europe in 2006 [4]. The closely coupled injection and ignition and the carefully optimized piston bowl for these SG SC engines improve fuel economy by enabling stratified operation over larger ranges of speed, load, and charge dilution [5]. However, the close coupling of injection and ignition subjects the developing flame to high velocities and intense turbulence. The spark plasma, the ignition kernel and the developing flame all are subjected to steep and varying gradients in the liquid and vapor concentrations and the velocity fields [6-12]. These factors can produce unfavorable conditions during ignition and early flame kernel growth, thereby increasing the frequency of partial-burn and misfire cycles and decreasing combustion efficiency (CE) [5]. There is also a trade-off between operation favorable to low soot and that favorable to low $\mathrm{NO}_{\mathrm{x}}$. High levels of residuals or EGR are used to minimize $\mathrm{NO}_{\mathrm{x}}$ emissions [13] but increase exhaust particulates and reduce combustion stability. The deterioration of combustion stability with EGR can be especially pronounced at higher engine speeds, where the magnitude of the flow variability can be higher [14]. These issues currently inhibit widespread implementation of SG SC DISI engines.

Flow evolution and its cycle-to-cycle variation are important in two ways. First, it has been shown [6, 7] that early flame-kernel growth can fail or be delayed when the flame kernel is convected away from the flammable fuel-air mixtures. Failed early kernel growth causes a complete misfire. Slow development of flame kernels into fully turbulent flames delays the main combustion period (i.e. $10 \%$ to $90 \%$ mass burned, CA10 - CA90), but does so differently from cycle to cycle. This, in turn, means that the main combustion experiences different flows, fuel-air mixing, and thermodynamic states from cycle to cycle. As a result, overly lean fuel-air mixtures may form, leading to incomplete combustion (i.e. a partial-burn cycle). Second, it has been reported [14-18] that the intake-generated flow momentum can be strong enough to change the liquid-spray development and turbulence level, which in turn introduces cycle-tocycle variability of fuel-air mixing and flame propagation. These observations point to the need to manage the in-cylinder flow development and reduce its cycle-to-cycle fluctuations.

Highly swirling flow has been successfully incorporated in both conventional gasoline and diesel engines to organize fuel-air mixing and combustion [19-23]. Swirl, possibly in combination with tumble and squish, is designed to promote large-scale transport of fuel-air mixture during fuel injection and to enhance the late-cycle mixing. In general, swirling flow can increase flame propagation speed and reduce cycle-to-cycle variations. On the other hand, generating rotational motion can have deleterious effects on volumetric efficiency as well as increase heat transfer which acts to reduce thermal efficiency. The effect of increased swirl on SG SC DISI combustion has been conducted previously using a combination of optical diagnostics and CFD simulation [24]. In that study the measured burning rates showed two-stage burning, which the companion simulations suggested is the result of initially turbulent partially-premixed flame propagation followed by mixing-dominated combustion of rich products. The simulation also predicted that increased swirl leads to localized rich burning. The effects of swirl were confirmed by the experimental imaging, which demonstrated that increased swirl increases the soot luminosity in the same rich-burning regions predicted by the CFD model. However, no direct measurements of the in-cylinder flow and its interaction with the spray and combustion were performed in that study.

Some insight into spray-swirl interaction can be gained from research efforts related to diesel combustion, which is inherently stratified and often incorporates a strong swirling flow. It can be summarized [25, 26] that the injection alters the flow field in the combustion chamber. The injection-swirl interaction was also 
shown to provide a mechanism by which a large fraction of the momentum of the fuel-injection event can be stored in the mean-flow rotation. However, these diesel engine studies cannot be used to fully explain effects of spray-swirl interaction on SG SC DISI combustion since SI engines rely on flame spread from a single location (as opposed to autoignition in multiple regions).

Previous studies of combustion variability in this SG SC DISI engine by the authors demonstrated that introducing swirl to the in-cylinder gas motion allows maintaining a low standard deviation of the indicated mean effective pressure (STD IMEP) as the engine speed is increased [27]. This motivated optical studies to reveal the stabilization mechanism of swirl for SG SC DISI combustion. As a first step, high-speed (HS) particle image velocimetry (PIV) measurements were conducted for non-fired operation in a horizontal swirl plane near the top of the piston bowl and in a central vertical tumble plane [27]. These measurements revealed that without injection, the swirl flow patterns in each cycle that are more similar to the ensemble-averaged cycle, and with decreased variability. In addition, the fuel injection redistributes the swirl angular momentum to create a very repeatable vortex and increase angular momentum close to the spray centerline. It was hypothesized that this improved motored-flow repeatability was responsible for the improved combustion stability at higher engine speed (2000 rpm). The goal of this study is to determine how a swirl-stabilized flow leads to more stable combustion. A previous study [15] revealed that poor-burn cycles (low IMEP) correlate with both late combustion phasing and low final mass fraction burned (FMFB). The combustion phasing varies due to flame-kernel growth, which is the time required for a flame to reach a developed state after the spark-ignition event [5]. Here, the flame-development time is defined as the period between the spark initiation and $4 \%$ mass burned fraction (CA04). CA04 is selected because the pressure measurements are sufficiently precise to provide reliable mass burn fraction (MBF) from the apparent heat-release rate (AHRR) analysis [28]. Also, flame imaging is used to investigate the period prior to CA04, which is early enough that the developing flame is within the optical field of view. Cycle-to-cycle variability of CA04 is effectively the same as variability of the spark timing (ST). This means that the flame at CA04 is presented with a different thermodynamic state, different point in the flow evolution, and the work is extracted differently. All three factors are forced by the piston motion. The final mass burned fraction in the SC DISI engine can be affected by cycle-to-cycle variations of the fuel-air mixing and turbulence after the early-flamekernel development period (CA04). In this study AHRR is relied upon to quantify the variability of the combustion after $\mathrm{CA} 04$, since not all regions of the unburned gas are visible; this is especially true near CA90 when the unburned gas may be near the cylinder wall and crevices.

The goal of this study is to understand the roles of early flame kernel growth and later burn for combustion variability, as well as to reveal the stabilization mechanism of swirl on these two periods. The analysis begins with steady-state performance tests conducted in an all-metal configuration of the SG SC DISI engine at 1000 and $2000 \mathrm{rpm}$, with and without swirl. Pressure-based AHRR analysis is used to demonstrate the degraded combustion stability at $2000 \mathrm{rpm}$, and the recovered stability with the addition of high swirl. The influence of swirl on the variability of $4 \%$ to $90 \%$ burn fractions (CA04 to CA90) is determined. The early, main and late combustion phases are then correlated with variations of both IMEP and combustion efficiency (i.e. FMFB). This provides a classification of CA10 and FMFB for poor and normal burns, and provides a basis of comparison for the skip-fired optical tests. The results with continuously-fired steady-state operation demonstrate that the skip-fired optical-engine operation results in similar CA04, FMFB, and AHRR variability.

High speed PIV measurements are presented for fired operation to demonstrate that the interaction of the spray and swirl flow observed in previous motored flow tests are unaffected prior to combustion. The variability of the local turbulent flow is quantified and correlated with CA10 variability to study the role 
of the swirl-stabilized flow for early stages of combustion. This serves to bridge the knowledge gaps between flow development and flame propagation. The PIV images also capture the convection of the spark plasma, which are used to quantify the differences between operation with and without swirl.

Flame imaging is conducted to reveal the role of the swirl flow for the transition from spark plasma to early flame kernel growth and subsequent flame propagation. Images of early flame kernel growth are correlated with the cycle-to-cycle variability of CA04. The flame spread is quantified by flame location PDFs, which are conditionally sampled to represent different types of AHRR variations.

AHRR and optical diagnostic results are integrated and summarized in the discussion, Sect. 4, which may have value as an overview prior to reading the body of the paper.

\section{Experimental Hardware and Methods}

\subsection{The Single-Cylinder Engine}

The single-cylinder four-valve research engine is operated in two configurations; an all-metal configuration for continuously fired performance testing, and in a geometrically identical optical piston and head configuration for imaging studies. The piston has a moderately deep piston bowl to aid the stratification of fuel. Figure 1 shows a cross section of the combustion chamber at top-dead-center (TDC) as well as the optical setup for PIV measurement. The piston-bowl rim for both metal and optical configurations has a cut-out on the right side (as viewed in Fig. 1) to allow better optical access into the bowl via the pent-roof side window (Fig. 1d). For optical operation, the engine is equipped with a quartz window in the end of the pent-roof section closest to the injector, and a quartz window in the piston bowl. Both windows are flat on the combustion-chamber side, just as the metal window blanks used for allmetal testing (see Figs. 1c \& 1d). The piston window is flat on the crank-case side for the PIV tests but concave for the flame-imaging tests, thereby creating a negative lens for a larger field of view. In-cylinder swirl flow is achieved in both configurations by deactivating the intake valve closest to the side window on the right-hand side. This creates a counterclockwise flow with a swirl ratio of 2.7 , as viewed from the piston window via a $45^{\circ}$ mirror.
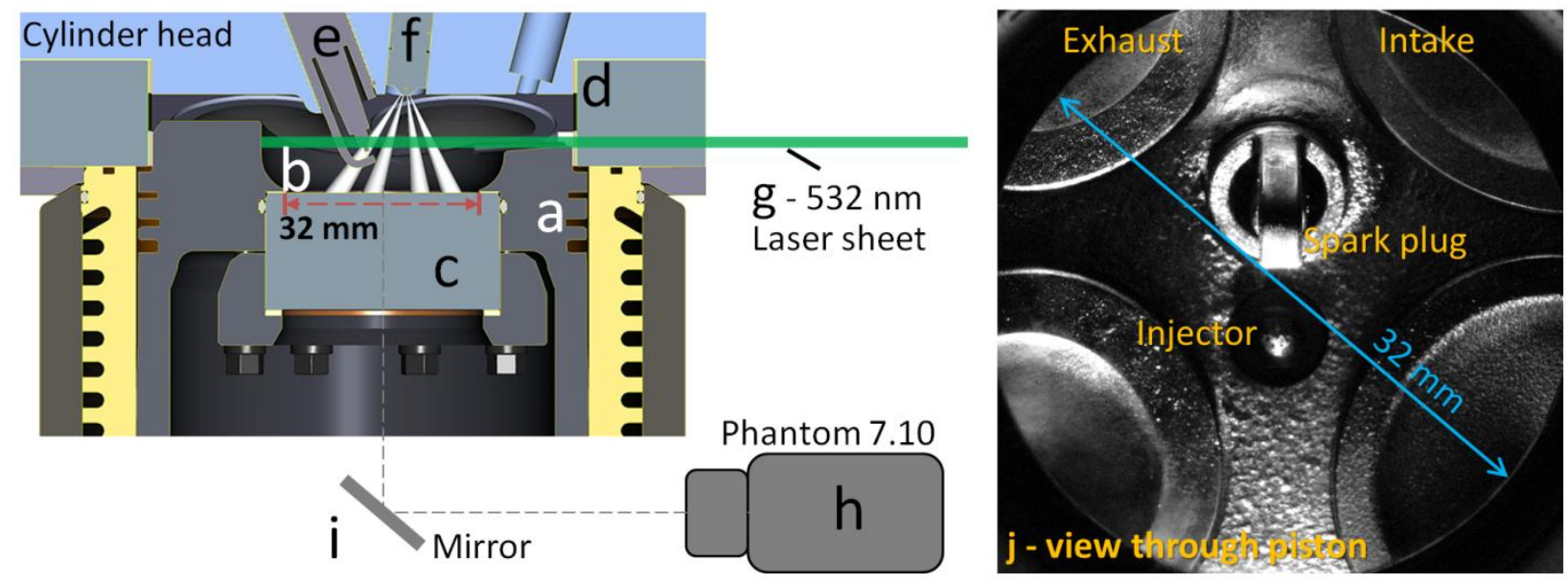

Fig. 1. Illustration of the cross-section of the combustion chamber at TDC with a) piston, b) piston bowl, c) pistonbowl window, d) pent-roof window, e) spark plug, and f - injector, setup for PIV measurement with g) laser sheet location, h) high-speed camera, i) Bowditch-piston mirror, and j) camera view through piston-bowl window (the lower-right valve is deactivated to generate the swirl). 
The engine was fueled using a centrally located 8-hole injector with a nominal included angle of $60^{\circ}$. A single-injection strategy with $12.6 \mathrm{mg}$ fuel mass was used for all operating conditions in this study. Compressed $\mathrm{N}_{2}$ is used to pressurize the piston-accumulator fuel reservoir, and this eliminates fuel-pumpinduced pressure pulses, resulting in cycle-to-cycle variability of fuel mass less than $0.5 \%$. The sparkplug gap is located $13 \mathrm{~mm}$ away from the injector tip. Similar to Ref. [14-16], here the injector was oriented such that two of the liquid-spray plumes straddled the spark-plug gap. The fuel used in this study was a high-octane certification gasoline with $(\mathrm{R}+\mathrm{M}) / 2=92.7$. The fuel was supplied by Haltermann Solutions and its specifications can be found in [29]. Nitrogen $\left(\mathrm{N}_{2}\right)$ dilution was used to lower the intake mole fraction of oxygen $\left[\mathrm{O}_{2}\right]$ to simulate EGR. The cam shafts were phased to provide both low residual levels ( $\approx 4-6 \%$ by mass) and high volumetric efficiency [15]. Some engine data are given in Table 1 and a more detailed description of the engine can be found in Ref. [30].

Table 1. Engine specifications and common operating conditions.

\begin{tabular}{lr}
\hline Displacement & 0.552 liters \\
Bore/Stroke & $86.0 / 95.1 \mathrm{~mm}$ \\
Connecting Rod Length & $166.7 \mathrm{~mm}$ \\
Geometric Compression Ratio & $12: 1$ \\
Intake Valve Diameter & $35.1 \mathrm{~mm}$ \\
Intake Valve Angle Relative Cylinder Axis & $18^{\circ}$ \\
Exhaust Valve Diameter & $30.1 \mathrm{~mm}$ \\
Exhaust Valve Angle Relative Cylinder Axis & $16^{\circ}$ \\
Swirl/Tumble Index & \\
One intake valve deactivated & $2.7 / 0.62$ \\
Two intake valves active & $0 / 0.27$ \\
Fuel Injector & Bosch 8-hole solenoid-type \\
Hole Orientation & Symmetric w/ $60^{\circ}$ included angle \\
Hole Size & Stepped-hole, min. dia. $=0.125 \mathrm{~mm}$ \\
Injection Rate @ 17 MPa & $13.3 \mathrm{mg} / \mathrm{ms}$ \\
Ignition Type & Inductive \\
Spark Coil & Bosch, ZS-L 1x1E \\
Spark Plug & Long-reach single-point J-gap \\
Spark Gap Width & $1.0 \mathrm{~mm}$ \\
Spark Energy & $106 \mathrm{~mJ}$ \\
Intake Temperature & $26-28^{\circ} \mathrm{C}$ \\
Intake Pressure (abs.) & $95 \mathrm{kPa}$ \\
Coolant Temperature & \\
Optical Operation & $90^{\circ} \mathrm{C}$ \\
All-metal Operation & $75^{\circ} \mathrm{C}$ \\
Injection Strategy & Single Injection \\
Injection Duration (command) & $0.95 \mathrm{~ms}$ \\
Injected Fuel Mass per Cycle & $12.6 \mathrm{mg}$ \\
Injection Pressure & $17 \mathrm{MPa}$ \\
\hline &
\end{tabular}

\subsection{High-Speed PIV}

The $6 \mathrm{kHz}$ planar PIV measurements provide an instantaneous two-dimensional (2-D) vector field every $1.0^{\circ} \mathrm{CA}$ at $1000 \mathrm{rpm}$ and every $2.0^{\circ} \mathrm{CA}$ at $2000 \mathrm{rpm}$. They were conducted in a horizontal plane just above 
the bowl at TDC (cf. Fig. 1) and near the spark-plug gap, capturing the principal components of the swirl flow.

The velocity field was measured over wide crank-angle ranges. Here, results are focused on the $-50^{\circ}$ to $32^{\circ} \mathrm{CA}$ ATDC range, quantifying and describing the flow before fuel injection, outside the spray during fuel injection, and in the post-injection entrainment vortex behind the liquid spray. Thus, the PIV measurements capture the flow during ignition and early flame kernel growth. Since the laser sheet illuminated both PIV-seeds and liquid spray during injection, spray structure was recorded simultaneously with the flow structure. In addition, the PIV images recorded the spark plasma which was used to compute the probability maps of spark-plasma location. Figure 1 also shows the setup for PIV measurement through the view of swirl plane. PIV images were recorded by a high-speed CMOS camera (Phantom v710), using frame straddling and 736 736 resolution. A $12 \mathrm{kHz}$ framing rate was used for both 1000 and $2000 \mathrm{rpm}$, which provides a vector field every $1.0^{\circ} \mathrm{CA}$ and $2.0^{\circ} \mathrm{CA}$, respectively. The PIV images were acquired through the piston-bowl window and a Bowditch-piston mirror that was installed just below the piston. A camera lens with a focal length (F.L.) of $180 \mathrm{~mm}$ was combined with a focallength doubler to image the $30 \times 30 \mathrm{~mm}^{2}$ area shown in Fig. 1 j. A $32 \times 32$ pixels PIV interrogation window provides an in-plane spatial resolution of $0.95 \mathrm{~mm}$, which is sufficient to resolve the expected flow scales in the 1 to $10 \mathrm{~mm}$ range [31]. PIV seed was provided by a six-jet atomizer (TSI 9306) producing silicone oil droplets with a nominal diameter of $1 \mu \mathrm{m}$ at a density of 15 to 20 particles per interrogation volume. Being oil based, the PIV seed is consumed by the flame and measurements are not available in the burned gas. The silicone oil droplets were illuminated by a $2 \mathrm{~mm}$ thick $532 \mathrm{~nm}$ laser sheet, which was directed through the pent-roof window, parallel to the bottom of the piston bowl, and located $1 \mathrm{~mm}$ above the spark-plug gap. As discussed in Ref. [16, 27], the relatively thick laser sheet degrades the in-plane spatial resolution, but reduces out-of-plane seeding particle loss between PIV frames. Multi-pass PIV crosscorrelation was used, with two passes for each reduction in window size from $128 \times 128$ to $32 \times 32$ pixels. $50 \%$ overlap was used resulting in vectors on a $0.475 \mathrm{~mm}$ grid spacing in both directions. Finally, a fivestep post-processing procedure was performed to remove bad vectors, similar to Ref. [16, 27].

Table 2. PIV setting and post-processing parameters

\begin{tabular}{lr}
\hline Time delay $(\Delta \mathrm{t})(1000 / 2000 \mathrm{rpm})$ & $10 / 7.5 \mu \mathrm{s}$ \\
Seed diameter & $1 \mu \mathrm{m}$ \\
Seed density & $15-20$ particles $/ 32 \times 32$ window \\
Valid-vector rate & $90 \%$ \\
Velocity dynamic range (1000 rpm) & $0.65-34 \mathrm{~m} / \mathrm{s}$ \\
Velocity dynamic range (2000 rpm) & $0.84-44 \mathrm{~m} / \mathrm{s}$ \\
In-plane spatial resolution & $0.95 \mathrm{~mm}$ \\
Sampling rate (1000/2000 rpm) & $6 \mathrm{kHz}\left(1.0^{\circ} / 2.0^{\circ} \mathrm{CA}\right)$ \\
\hline
\end{tabular}

PIV measurement accuracy and resolution depend on the pixel resolution of interrogation window, particle image size, particle number density, thickness of laser sheet, and time delay between images $(\Delta \mathrm{t})$ [32]. Here, the PIV uncertainty was evaluated using the velocity-error analysis approach presented in Ref. [16,33]. The PIV experimental settings, summarized in Table 2, were designed to achieve a maximum in-plane particle displacement of eight pixels to avoid biasing the velocity towards low values. As presented in Table 2, the time delays for 1000 and $2000 \mathrm{rpm}$ are 10 and $7.5 \mu \mathrm{s}$, respectively. Therefore, eight pixels correspond to maximum velocity magnitudes of $34 \mathrm{~m} / \mathrm{s}$ and $44 \mathrm{~m} / \mathrm{s}$, for 1000 and $2000 \mathrm{rpm}$, 
respectively. The most optimistic velocity resolution is 0.15 pixel RMS based on the RMS noise of real images [34]. Thus, the measured velocities here have RMS uncertainties of $0.65 \mathrm{~m} / \mathrm{s}$ and $0.84 \mathrm{~m} / \mathrm{s}$ for 1000 and $2000 \mathrm{rpm}$, respectively. Hence, the dynamic ranges are $0.65-34 \mathrm{~m} / \mathrm{s}$ for $1000 \mathrm{rpm}$, and $0.84-$ $44 \mathrm{~m} / \mathrm{s}$ for $2000 \mathrm{rpm}$. Vector analysis in the measurement range shows that more than $85 \%$ of all velocities fall within these dynamic ranges. This indicates that the measurement noise is relatively small throughout crank-angle range presented here.

\subsection{Natural Flame-Luminosity Imaging}

The PIV camera was adjusted to capture the laser light scattered from PIV seed particles and highintensity plasma discharge, but could not allow concurrently record the much weaker chemiluminescence from early flame kernels. Thus, flame imaging via the piston-bowl window was conducted separately to record early flame kernels as well as more developed flames during later portions of the combustion events.

For the early flame kernel, $\mathrm{OH}^{*}(308 \mathrm{~nm})$ chemiluminescence is arguably the best indicator of flamefront location for a wide range of flames [35, 36], but requires a UV sensitive image intensifier. However, it is challenging to image low intensity early flame kernel for stratified spark-ignited engine combustion because intensifier exposures of sufficient duration to image the low intensity early flame kernel can be damaging to the intensifier due to the presence of bright spark plasma and soot luminosity. Here, an unintensified, high-speed color camera (Phantom V611) is used to record broadband luminosity of early flame kernel and subsequent flame propagation. Figure 2 presents the camera's spectral response and shows that the spectral sensitivity for $\mathrm{OH}^{*}$ emissions is low. However, other flame chemiluminescence emissions are present in the flame during early flame kernel growth, such as $\mathrm{CH}(430 \mathrm{~nm})$ and $\mathrm{C}_{2}(520$ nm) [36], which can be captured by the color camera.

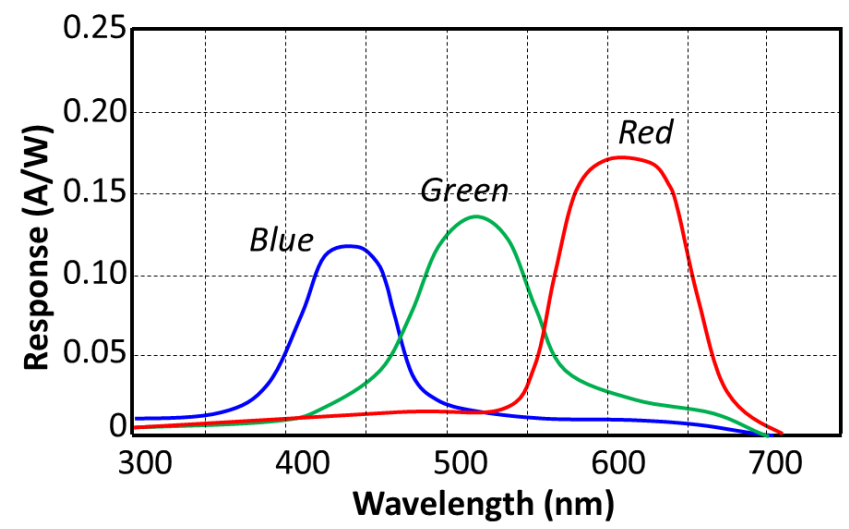

Fig. 2. Spectral response of blue, green and red for color camera (replotted based on Phantom v611 color camera sensor specification)

Figure 3 shows the optical setup used to compare the early flame kernel image of the "natural" luminosity captured by the unintensified color camera to $\mathrm{OH}^{*}$ images. Images were recorded simultaneously with the V611 color camera and a UV-sensitive intensified high-speed CMOS camera (Phantom V7.1, 308 $\pm 10 \mathrm{~nm}$ bandpass filter, $105 \mathrm{~mm}$ F.L. f/4.5 UV Nikor lens). Images were recorded every $0.5^{\circ} \mathrm{CA}$ through the piston-bowl window. A $350 \mathrm{~nm}$ dielectric mirror reflected the $\mathrm{OH}^{*}$ chemiluminescence to the intensified camera and transmitted the other emissions to the color camera. Both cameras were operated at $12 \mathrm{kHz}$ 
and $24 \mathrm{kHz}$ framing rates for 1000 and $2000 \mathrm{rpm}$, respectively. For the color camera, a 416×416 pixel image size was used, and $256 \times 256$ for the intensified camera.

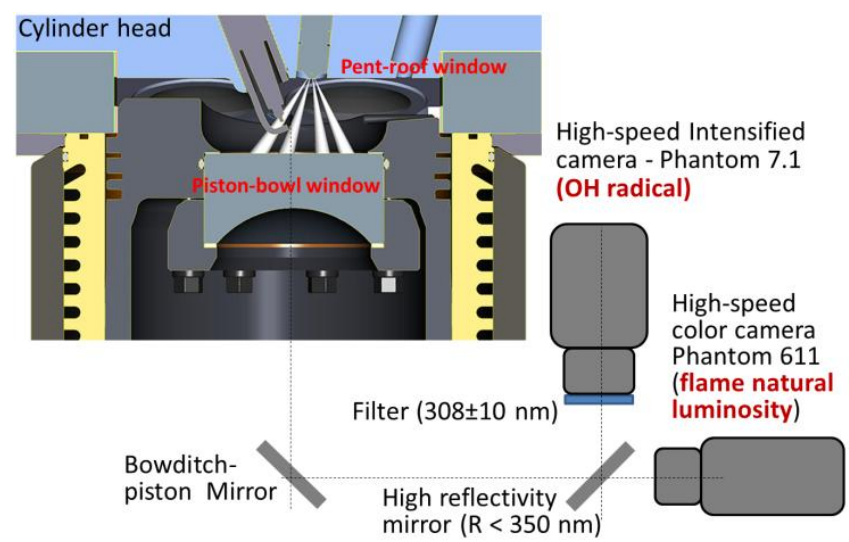

Fig. 3. Optical setup for simultaneous $\mathrm{OH}^{*}$ and natural flame luminosity imaging

Figure 4 shows individual images and corresponding contours for five randomly selected cycles at $27^{\circ} \mathrm{CA}$ ATDC. It provides comparisons of blue-pixel images with $\mathrm{OH}^{*}$ images for operation with swirl at $2000 \mathrm{rpm}$ (Test 3 of Table 3). For both $\mathrm{OH}^{*}$ chemiluminescence and broadband blue flame luminosity images, the flame contours use a threshold of $10 \%$ of maximum intensity. Although the flame contours are not identical for the two cameras, the correspondence is sufficient for the estimates of the flame growth rate and flame location of interest here.

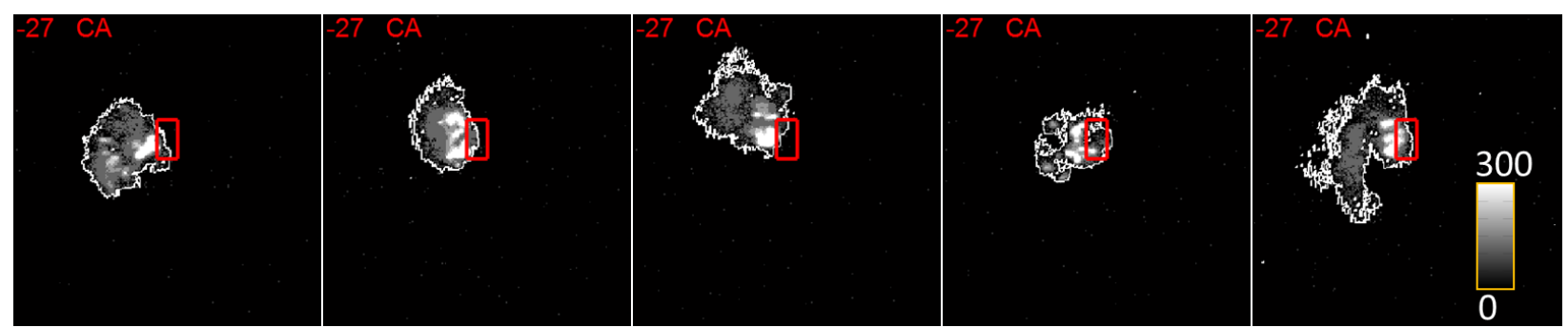

(a) Color camera - blue signal

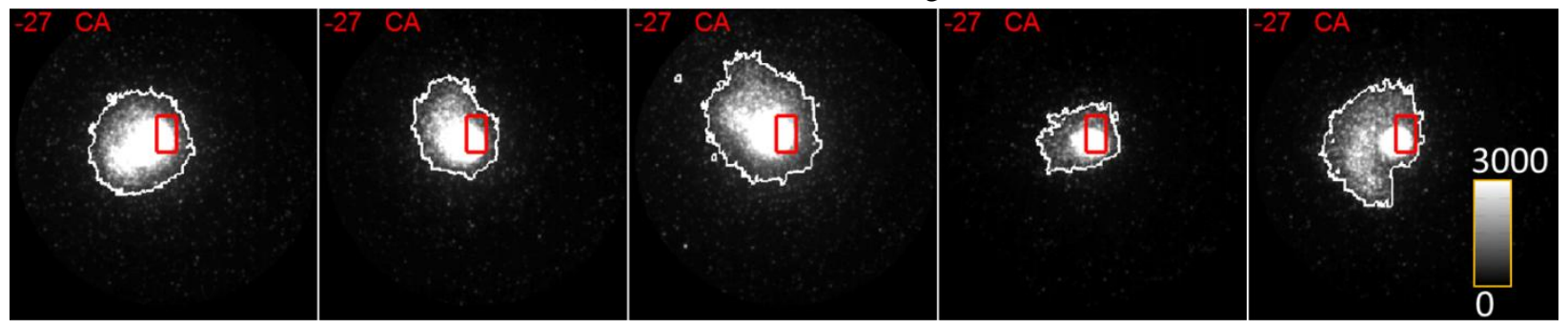

(b) Intensified camera - $\mathrm{OH}^{*}$ signal

Fig. 4. Comparison of (a) blue-pixel images to (b) $\mathrm{OH}^{*}$ images from five randomly selected individual cycles at $27^{\circ} \mathrm{CA}$ ATDC. Operating conditions correspond to Test 3 of Table 3.

Figure 5 shows 2D-probability maps of $\mathrm{OH}^{*}$ flame and blue-pixel flame locations obtained using 100 individual images at $-27^{\circ} \mathrm{CA}$ and $-23^{\circ} \mathrm{CA}$ ATDC. The probability maps are created by using a $10 \%$ peak intensity threshold to binarize the individual cycle flames following the method in Ref. [13, 14]. (The smoother contours observed in the $\mathrm{OH}^{*}$ images are partly due to the filtering applied to the more granular images acquired with the lower-spatial resolution intensified camera. Also, the signal in the blue channel of the color camera is close to the noise floor of the CMOS detector.) However, it can be observed that 
flame location gained from the color camera is similar to that from the intensified camera. It provides evidence that $\mathrm{OH}^{*}$ chemiluminescence imaging and natural flame luminosity imaging capture similar flame location and the color camera is capable of detecting the early flame kernel. Therefore, the color camera was used to acquire data for all operating conditions shown in Table 3 from $-50^{\circ} \mathrm{CA}$ to $20^{\circ} \mathrm{CA}$ ATDC, covering CA range for fuel injection, spark ignition, early flame formation and growth, and subsequent main combustion.

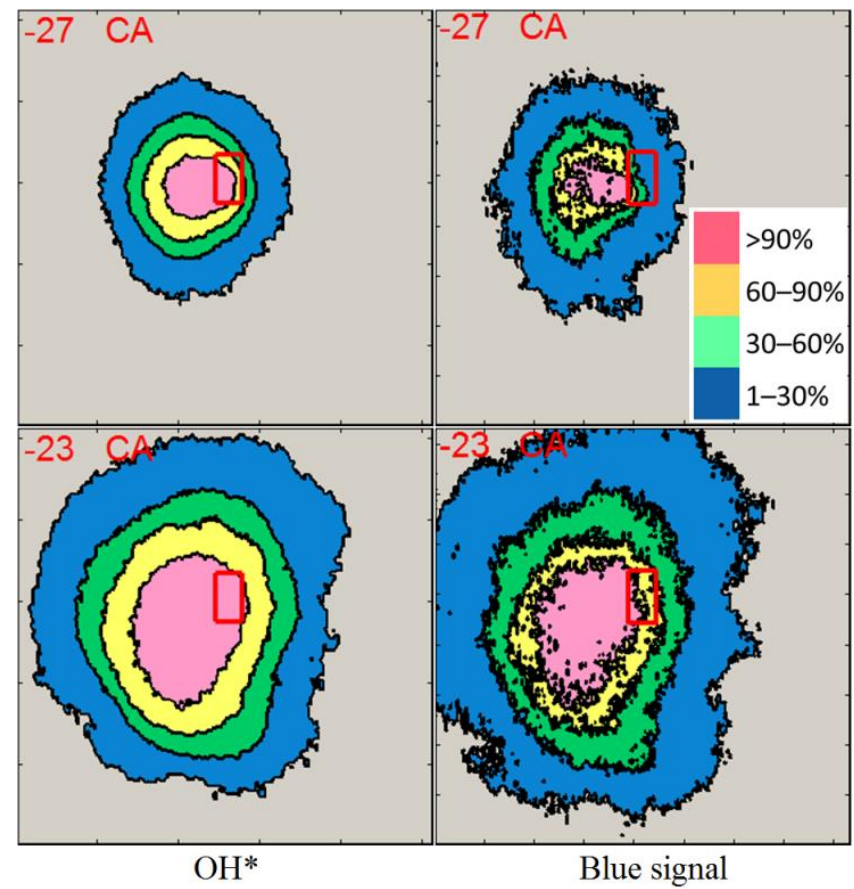

Fig. 5. Probability maps of $\mathrm{OH}^{*}$ image and "blue" flame locations sampled over 100 cycles.

\subsection{Engine Operation}

The all-metal engine was continuously fired to determine the operating points desired for this study, and to measure the exhaust emissions. The metal-engine tests were used as the basis of comparison to assure that the combustion during optical-engine operation had sufficiently similar burning rates and stability. Testing was conducted with (one intake valve) and without (both intake valves) intake-generated swirl flow at both 1000 and $2000 \mathrm{rpm}$. The swirl was varied to reveal effects of differences in flow repeatability on combustion variability. The engine speed variation was imposed to reveal effects of changes in the gas-flow momentum on combustion variability.

The intake temperature, intake pressure and injection duration were kept constant for all test conditions. The in-cylinder pressure, spark current, intake and exhaust pressure, and fuel pressure were acquired with $0.1^{\circ} \mathrm{CA}$ resolution. The apparent heat-release rate (AHRR) was computed from the in-cylinder pressure for each individual cycle using a constant ratio of specific heats $(\gamma)$ following Ref. [28]. The combustion efficiency was computed from the emissions and used to scale the average cumulative AHRR; thus, the final mass burned fraction (FMBF) based on the AHRR is a measure of the combustion efficiency of each cycle. With this approach, the combustion efficiency for some cycles is estimated to be higher than $100 \%$. This is partly explained by extra unburned fuel in residuals for cycles that follow misfire or partial-burn cycles. It should be noted that the valve timings were selected to achieve low residual level. For the current data sets, the residual mass fraction is roughly $5 \%$ following well-burning cycles [15]. For misfire cycles, the lower gas temperature increases the residual mass fraction to $\approx 9 \%$, which increases the available chemical energy sufficiently that Fig. 8 (section 3.1) displays a cycle with FMFB as high as 

AHRR caused by factors like heat-transfer variability. To quantify combustion variability, the standard

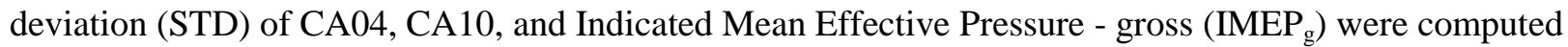
for each operating point.

The steady-state metal-engine tests of 500-cycle duration were conducted with the variables shown in Table 3, which includes the engine speed, swirl index, injection- and spark-timings. The test conditions in Table 3 were conducted with $\mathrm{N}_{2}$ dilution set to maintain $\left[\mathrm{O}_{2}\right]$ at $19 \%$. The start of actual injection $\left(\mathrm{SOI}_{\mathrm{a}}\right)$ and ST for Tests 1-4 were adjusted to achieve the most stable combustion for each operating point. The selected $\mathrm{SOI}_{\mathrm{a}}$ and $\mathrm{ST}$ also produce a $50 \%$ burn fraction (CA50) that is located at $-8.0 \pm 1.5^{\circ} \mathrm{CA}$.

Table 3. Test conditions for all-metal engine operation $\left(\left[\mathrm{O}_{2}\right]=19 \%\right)$ and simultaneous $\mathrm{OH}^{*}$ and flame natural luminosity imaging $\left(\left[\mathrm{O}_{2}\right]=19 \%\right)$

\begin{tabular}{cccccc}
\hline Test & Speed & Swirl Index & $\mathrm{SOI}_{\mathrm{a}}$ & $\mathrm{EOI}_{\mathrm{a}}$ & $\mathrm{ST}$ \\
1 & $1000 \mathrm{rpm}$ & 2.7 & $-31^{\circ} \mathrm{CA}$ & $-24^{\circ} \mathrm{CA}$ & $-24^{\circ} \mathrm{CA}$ \\
2 & $1000 \mathrm{rpm}$ & 0 & $-31^{\circ} \mathrm{CA}$ & $-24^{\circ} \mathrm{CA}$ & $-24^{\circ} \mathrm{CA}$ \\
3 & $2000 \mathrm{rpm}$ & 2.7 & $-49^{\circ} \mathrm{CA}$ & $-36^{\circ} \mathrm{CA}$ & $-36^{\circ} \mathrm{CA}$ \\
4 & $2000 \mathrm{rpm}$ & 0 & $-49^{\circ} \mathrm{CA}$ & $-36^{\circ} \mathrm{CA}$ & $-36^{\circ} \mathrm{CA}$ \\
5 & $2000 \mathrm{rpm}$ & 2.7 & $-49^{\circ} \mathrm{CA}$ & $-36^{\circ} \mathrm{CA}$ & $-35^{\circ} \mathrm{CA}$ \\
6 & $2000 \mathrm{rpm}$ & 0 & $-49^{\circ} \mathrm{CA}$ & $-36^{\circ} \mathrm{CA}$ & $-35^{\circ} \mathrm{CA}$ \\
\hline
\end{tabular}

Table 4. Test conditions for PIV measurements $\left(\left[\mathrm{O}_{2}\right]=16.5 \%\right)$

\begin{tabular}{cccccc}
\hline Test & Speed & Swirl Index & $\mathrm{SOI}_{\mathrm{a}}$ & $\mathrm{EOI}_{\mathrm{a}}$ & $\mathrm{ST}$ \\
1 & $1000 \mathrm{rpm}$ & 2.7 & $-31^{\circ} \mathrm{CA}$ & $-24^{\circ} \mathrm{CA}$ & $-25^{\circ} \mathrm{CA}$ \\
2 & $1000 \mathrm{rpm}$ & 0 & $-31^{\circ} \mathrm{CA}$ & $-24^{\circ} \mathrm{CA}$ & $-25^{\circ} \mathrm{CA}$ \\
3 & $2000 \mathrm{rpm}$ & 2.7 & $-47^{\circ} \mathrm{CA}$ & $-34^{\circ} \mathrm{CA}$ & $-35^{\circ} \mathrm{CA}$ \\
4 & $2000 \mathrm{rpm}$ & 0 & $-47^{\circ} \mathrm{CA}$ & $-34^{\circ} \mathrm{CA}$ & $-35^{\circ} \mathrm{CA}$ \\
\hline
\end{tabular}

Both the flame-imaging and PIV optical-engine tests were conducted with a 25\% duty cycle. A Fire2Skip6 sequence was used for all optical-engine operation to reduce the thermal load on the quartz windows. All the data were acquired during the second fired cycle to achieve more representative temperature and composition of the residual gases. A higher coolant temperature of $90^{\circ} \mathrm{C}$ was used for optical operation compared to $75^{\circ} \mathrm{C}$ for the metal-engine operation to compensate for the lower duty cycle, leading to similar combustion-chamber surface temperatures (as measured in the cylinder head) for all operating points.

The PIV tests were conducted for direct comparison with the motored tests of Ref. [27], to demonstrate that the conclusions about the flow trends between engine speed and swirl, drawn from the analysis of the motored flow, are still valid with combustion. Here, higher $\mathrm{N}_{2}$ dilution $\left(\left[\mathrm{O}_{2}\right]=16.5 \%\right)$ was used, which required the spark timing relative to the injection to be advanced by $1^{\circ} \mathrm{CA}$, compared to the current metal engine combustion and flame imaging tests $\left(\left[\mathrm{O}_{2}\right]=19 \%\right)$ (cf. Tables $\left.3 \& 4\right)$. This slight difference from the more optimized combustion operation here does not detract from these results, since only trends (rather than direct quantitative comparisons) between the flow metrics and combustion performance are considered here. For each operation point, 50 cycles of combined PIV and pressure data were acquired. The engine speeds and swirl indexes are the same as those of the all-metal engine experiments. A previous study demonstrated that low $\left[\mathrm{O}_{2}\right]$ is desirable for low $\mathrm{NO}_{\mathrm{x}}$, but the early flame weakens to the point of being susceptible to variations of flow, thereby, elevating the combustion variability [14]. This 

in Fig. 6. Another effect of a lower $\left[\mathrm{O}_{2}\right]$ for the PIV tests is that CA10 and CA50 are retarded as shown in Fig. 6. This allows PIV measurements to continue longer after ST since the consumption of PIV oil particles is delayed. Figure 6a also shows that the trends of STD CA10 with changes in engine speed and swirl (Tests 1-4) are similar for both $16.5 \%$ and $19 \%$ operation. The ramifications of the added dilution for the PIV tests will be discussed after presentation of the results.

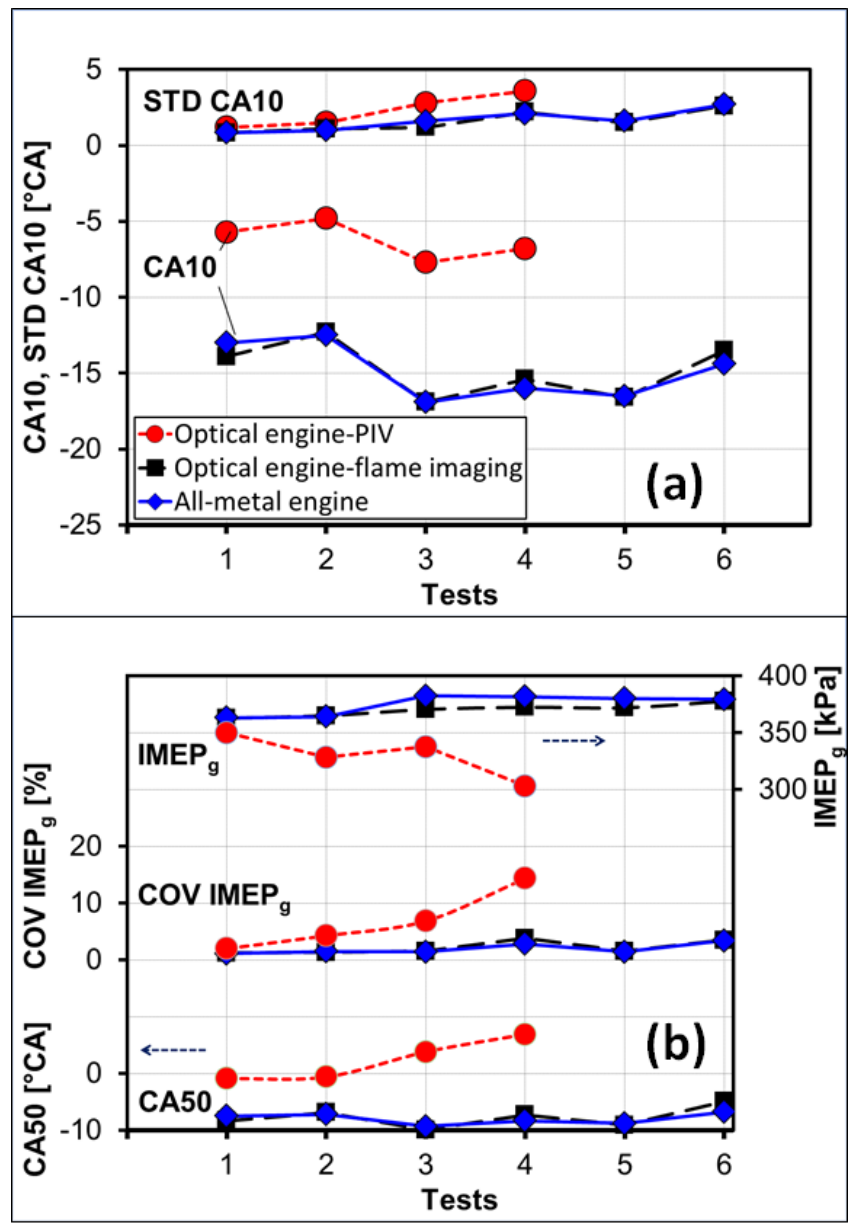

Fig. 6. Test averaged heat release and pressure analyses comparing steady-state metal-engine and skip-fired opticalengine operation. Occasional misfires have been excluded from these analyses

The flame imaging tests (Tests $5 \& 6$ ) were conducted at the same conditions as the metal-engine tests ( $3 \& 4$ ) but with the spark timing retarded from $-36^{\circ} \mathrm{CA}$ to $-35^{\circ} \mathrm{CA}$ as indicated in Table 3 . The number of sample cycles for flame-imaging is 100 , which is larger than that for PIV measurement. This was done to create a statistically larger sample of poor-burn cycles; ramifications of this are discussed in the results. Along with the flame imaging data, in-cylinder pressure data were acquired simultaneously to provide a combustion heat-release rate based conditional analysis. Except for being skip-fired with elevated coolant temperature, Table 3 shows that the operating conditions are the same as for all-metal engine experiments. Figure 6 demonstrates a good agreement between the steady-state metal-engine and opticalengine experiments. Occasional misfires $(\leq 1 \%)$ occurred for Test 6 in Table 3 and for Tests 3 and 4 in Table 4. The Test 6 of all-metal engine operation shows the highest frequency of misfire (1\%). These misfire cycles were excluded from the statistics shown in Fig. 6, allowing a focused investigation of the occurrence of partial-burn cycles. A discussion of the occurrence of misfires in spray-guided stratifiedcharge engines can be found in Ref. [5, 6]. 


\section{Results}

\subsection{Influence of Swirl and Engine Speed for Steady-State Metal-Engine Operation}

To demonstrate the effect of swirl flow on combustion variability, 500-cycle tests with continuously fired steady-state operation were carried out in the metal engine at 1000 and $2000 \mathrm{rpm}$. To achieve comparable thermodynamic conditions, the combustion phasing was adjusted to achieve CA50 $=-8.0 \pm 1.5^{\circ} \mathrm{CA}$ (refer to Table 3 and Fig. 6) by adjusting SOI and ST. The ST coincides with the end of injection (EOI), igniting the tail of liquid spray, as reported in Ref. [30], to achieve the most stable operation. The results at 1000 rpm in Fig. 7a demonstrate that operation without swirl is reasonably stable (STD IMEP $=5.5 \mathrm{kPa}$ ), and even more stable with swirl $\left(\right.$ STD IMEP g $\left._{2} 4.1 \mathrm{kPa}\right)$. However, operation without swirl at $2000 \mathrm{rpm}$,

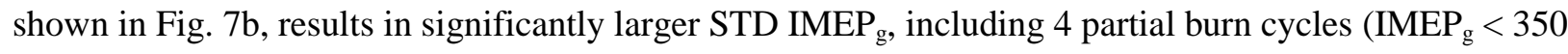
$\mathrm{kPa}$ ). Figure 8a shows a good correlation between the IMEP and FMFB for operation both with and without swirl (Tests 3 and 4 in Table 3). Here the FMFB from the AHRR analysis is used as an estimate of the combustion efficiency of each cycle. It clearly demonstrates that the good-burn cycles (high IMEP $_{\mathrm{g}}$ ) have the same range of FMFB and $\mathrm{IMEP}_{\mathrm{g}}$, and in fact implies that the low IMEP cycles are due to incomplete combustion. This correlation holds true for relatively weak cycles $\left(350 \mathrm{kPa}<\mathrm{IMEP}_{\mathrm{g}}<370 \mathrm{kPa}\right.$, $90 \%<\mathrm{FMFB}<93 \%$ ) as well as the partial burn cycles defined here as $\mathrm{IMEP}_{\mathrm{g}}<350 \mathrm{kPa}, \mathrm{FMBF}<90 \%$. Of course, low $\mathrm{IMEP}_{\mathrm{g}}$ can result from both poor work extraction and incomplete combustion. Using CA50 as the metric for combustion phasing, Fig. 8b demonstrates that the marginal and partial-burn cycles can have the same phasing as the good cycles, and that good cycles can have very late phasing.

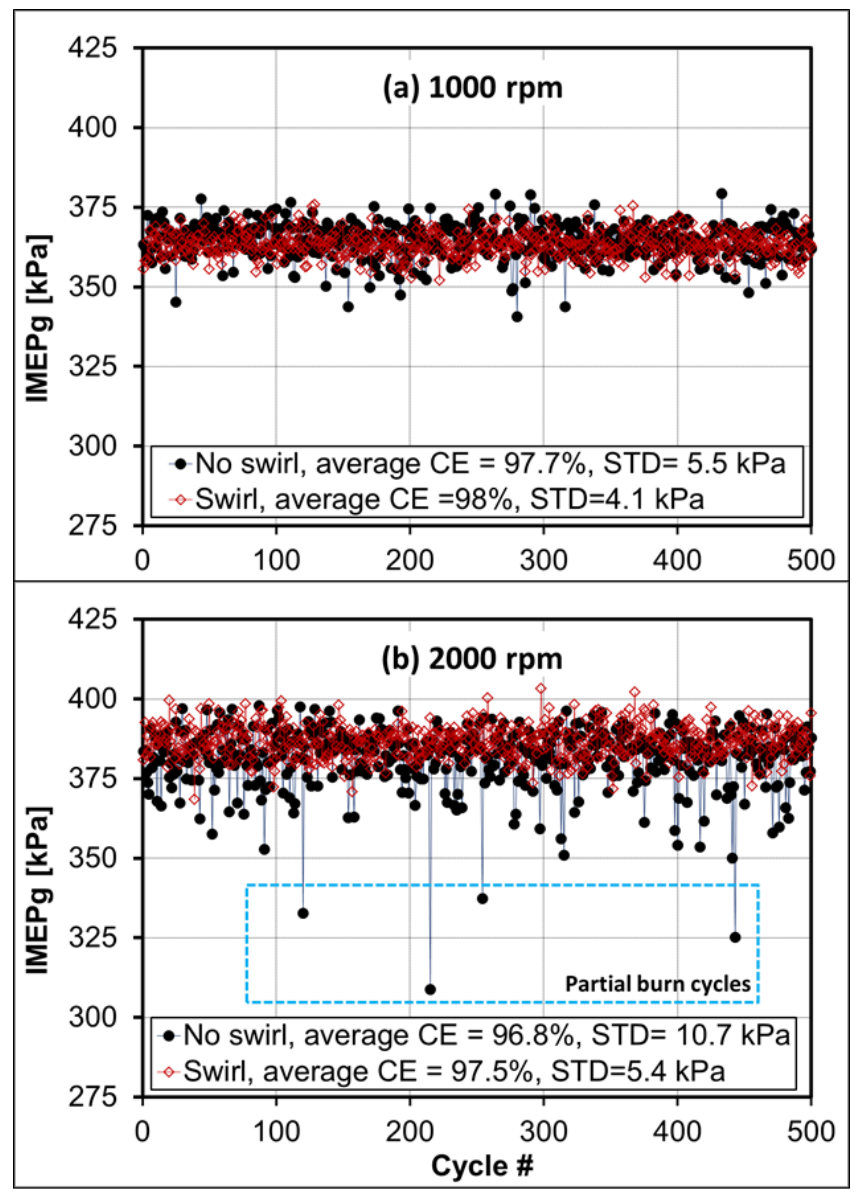

Fig. 7. Cycle-to-cycle variations of IMEP ${ }_{g}$ for 1000 and $2000 \mathrm{rpm}$ with and without swirl (Tests 1-4 in Table 3), noting the standard deviation of IMEP $_{\mathrm{g}}(\mathrm{STD})$, and combustion efficiency (CE). 


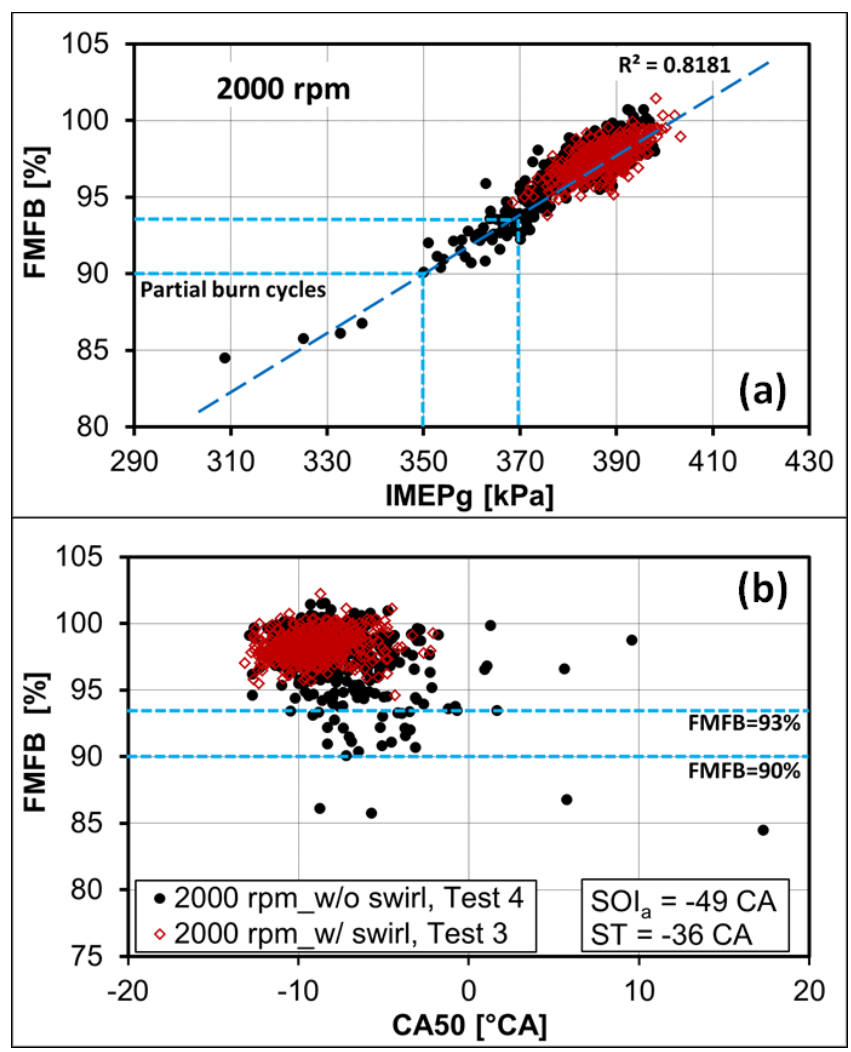

Fig. 8. Correlation between IMEP $_{\mathrm{g}}$ and CA50 with FMFB at $2000 \mathrm{rpm}$, with and without swirl (Tests 3 and 4 in Table 3)

Figures 7 and 8 demonstrate that swirl flow leads to more stable combustion at both engine speeds. However, the following analysis focuses on $2000 \mathrm{rpm}$ since the impact of swirl flow on combustion variability is more significant, making AHRR analysis more tractable.

The observations in Figures 7 and 8 suggest that cycles that initially burn slowly can speed up and burn to completion (high FMFB), but also that cycles initially burn fast can become too slow to complete combustion. Further insight is provided in Figures $9 \mathrm{a}$ and $9 \mathrm{~b}$, by investigating the relationship of the burning quality (i.e. $\mathrm{IMEP}_{\mathrm{g}}$ ) versus the early and late phases of combustion (CA04 through CA90, and CA90-CA50). Figure 9a (2000 rpm, swirl) demonstrates that good-burn cycles have small early-burn variability at a given IMEP $_{\mathrm{g}}(\mathrm{CA04}$ through and including CA50) but that the burning variability increases during the late portion of the cycles as indicated by CA90 variability, and emphasized by the variability of CA90-CA50. However, with swirl there is apparently sufficient time for the late-burn cycles to achieve $95 \%$ combustion efficiency and $370 \mathrm{kPa}$ IMEP $_{\mathrm{g}}$. Figure $9 \mathrm{~b}$ (2000rpm, no swirl) shows the same trend, but further, as $\mathrm{IMEP}_{\mathrm{g}}$ decreases the CA90 advances until about $\mathrm{CA} 90=50^{\circ} \mathrm{CA}$ ATDC when partial burns occur. This points to burning variability between CA90-CA50 as a major cause of

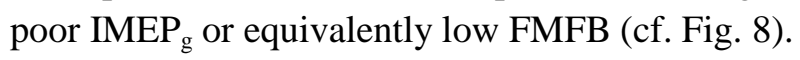

The increased random variability of CA04 through CA50 suggests that cycle-to-cycle variability of combustion phasing could also be caused by the duration of the early kernel flame development; that is, the transition from the start of ignition, ST, to turbulent flame propagation. Here, CA04 is used to separate the duration of the early flame-kernel development from later combustion, as it is sufficiently 
late that the early flame already reaches the edge of the optical field of view, yet late enough ${ }^{1}$ to be captured by the pressure-based AHRR analysis. Figure 9c shows linear regressions of CA10 through CA90 vs. CA04, which quantify the increased statistical combustion variability with later MFB. However, the large range of CA04 and increased variability in combustion phasing and duration (Fig. 9b) reveal that both early flame kernel variability and slow burning of late MFB can contribute to any particular poor-burn cycle.
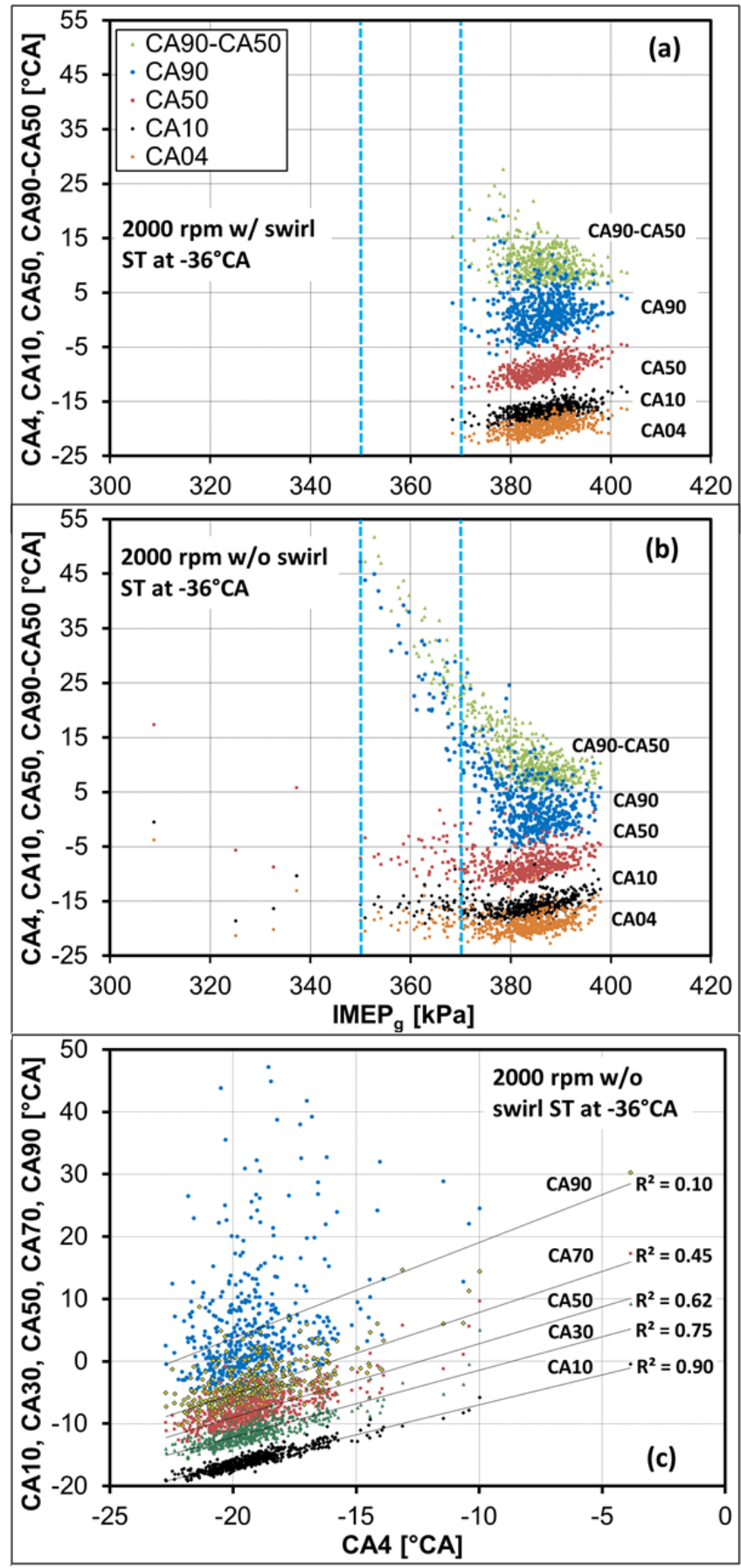

Fig. 9. AHRR analysis of early to late stages of combustion for 500 cycles in the continuously-fired metal engine $2000 \mathrm{rpm}$, with and without swirl

\footnotetext{
${ }^{1}$ This is reasonably substantiated by $\mathrm{R}^{2}=0.9 \mathrm{in} \mathrm{Fig.} 9 \mathrm{c}$ for CA04 vs CA10. Here, CA04 is used as the earliest reliable MFB.
} 
The following optical analysis focuses on the early kernel flame-development and stratified combustion prior to TDC, still at $2000 \mathrm{rpm}$. The approach is to conditionally sample cycles based on CA10 and FMFB. Operating conditions of Table 3, Tests $5 \& 6$ were used, where ST is retarded from $-36^{\circ} \mathrm{CA}$ to $35^{\circ} \mathrm{CA}$ and other operating parameters are the same as Tests 3 and 4 . Since a tail-ignition strategy ( $\mathrm{ST} \cong \mathrm{EOI}$ ) is used, the retarded ST in Tests $5 \& 6$ results in more cycle-to-cycle variability, and a desired larger sample of partial-burn cycles for statistical analysis. Figure 10 presents CA10 variations and highlights the partial-burn cycles for Tests 3, 4, and 6, but sorted from the smallest to largest CA10. Tests $3 \& 4$ show the range of CA10 with $\mathrm{ST}=-36^{\circ} \mathrm{CA}$, with and without swirl, respectively. For Test 4 , $\mathrm{ST}=-36^{\circ} \mathrm{CA}$ without swirl, 2 out of 4 partial-burn cycles occur, highlighted as yellow circles, inside the dashed red rectangle. For the retarded timing $\mathrm{ST}=-35^{\circ} \mathrm{CA}$ without swirl, 6 out of 10 partial-burn cycles experienced an extremely delayed CA10 (highlighted as yellow squares). These also indicate that there is a relatively high risk for early-burn delayed cycles to turn into a partial burn (as highlighted in Figure 10 using a red rectangle). Operation with swirl (Test 3) does not have cycles with very late CA10, reducing the risk of partial burns.

The results of the steady-state tests can be summarized as follows. First, both early (CA10) and mid-late (CA90-CA50) burns contribute to combustion variability. Second, cycles with a delayed early burn may recover but have a higher risk to turn into a partial burn. Third, the swirling flow here suppresses cycle-tocycle variations of stratified-charge combustion. The results in Figs. 7 through 10 are of course specific to the operating conditions of this particular engine. However, they do demonstrate that the pressure-based combustion metrics (and their cycle-to-cycle variability) for this operation are consistent with the operation of other spray-guided stratified-charge engines using multi-hole direct-injection [5]. Thus, it is expected that the physical processes of flow and combustion observed in the results below have application beyond this engine.

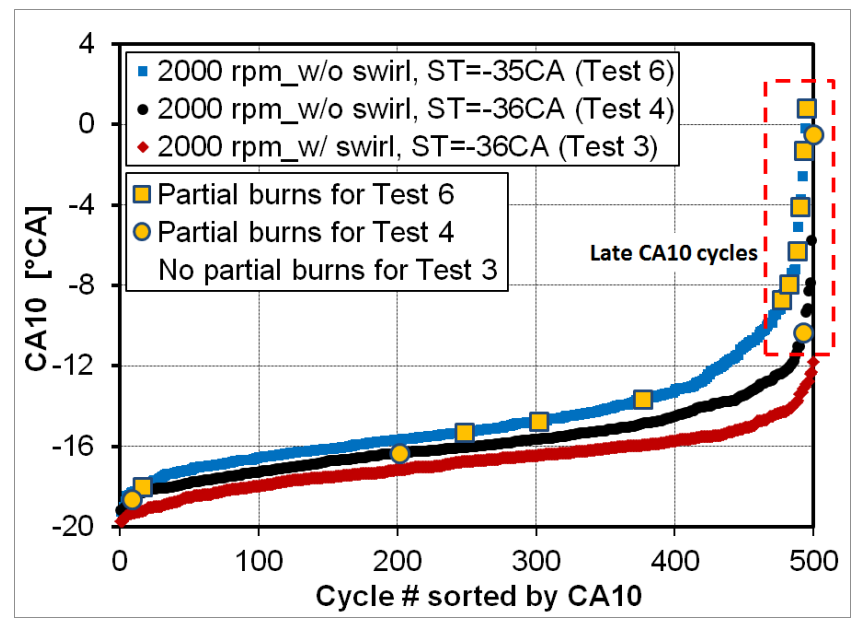

Fig. 10. Cycle-to-cycle variations of CA10 for $2000 \mathrm{rpm}$ with and without swirl (Tests 3, 4 and 6 of Table 3); Cycle \# sorted from the smallest to largest of CA10.

\subsection{Correlation of Flow with Early-Burn Variability - HS-PIV}

Previously, high-speed 2D PIV measurements have been made for operation without ignition, revealing fluid dynamics of swirl stabilization and leading to a conceptual model of gas-flow redistribution by spray-swirl interaction [27]. In this section, the PIV measurements are conducted to demonstrate that this conceptual model is still valid for fired operation. Next, the cycle-to-cycle variability of the flow 
presented to the spark discharge and early flame period is quantified and shown to correlate with the combustion variability (for both engine speeds, with and without swirl).

Figure 11 presents mean flow structure obtained using 50 individual cycles at Tests 3 and 4 in Table 4 . This demonstrates that, with intake-generated swirl, fuel injection causes a distinct redistribution of angular momentum resulting from spray-flow interaction. This centers and strengthens the swirl vortex in the piston bowl and creates a uniform distribution of vector magnitude around the vortex (as indicated by color vectors). These observations agree with the conceptual model derived from the motored flow in Ref. [27]. Here, a clear swirl vortex can be observed for all individual cycles until $-30^{\circ} \mathrm{CA}$ ATDC $\left(4^{\circ} \mathrm{CA}\right.$ after spark timing) as long as the PIV oil particles are not consumed by combustion. Figures $12 \mathrm{a}$ and $12 \mathrm{~b}$ show vector fields from three individual cycles at $-48^{\circ} \mathrm{CA}$ ATDC (before injection) and $-30^{\circ} \mathrm{CA}$ ATDC (a few crank angles after the end of injection), respectively. Without swirl each cycle presents a very different large-scale flow to the spark plug. With swirl, individual cycles are similar to the ensemble mean, especially for the flow patterns after injection. This was quantified for the motored results in Ref. [27], where the relevance index $\left(\mathrm{R}_{\mathrm{p}}\right)$ was used to quantify the similarity and repeatability of the flow patterns [37, 38]. This redistribution by the spray of the in-cylinder flow generated by the intake stroke was originally demonstrated by Miles [26] in a small-bore compression-ignition engine, with a flat head and highly reentrant bowl. This redistribution was then observed in this motored SI engine, which is a 4valve engine with a pent-roof combustion chamber, open piston bowl and a lower compression ratio [27]. The occurrence in such different engines implies a universality of the concept in reciprocating engines that employ piston bowls and high swirl. The combustion results here reaffirm the motored-flow results of Ref. [27]: the liquid spray stabilizes the flow field by redistributing the gas-phase swirl-flow momentum to create a repeatable and higher angular-momentum vortex close to the spray centerline, with reduced cycle-to-cycle variability.

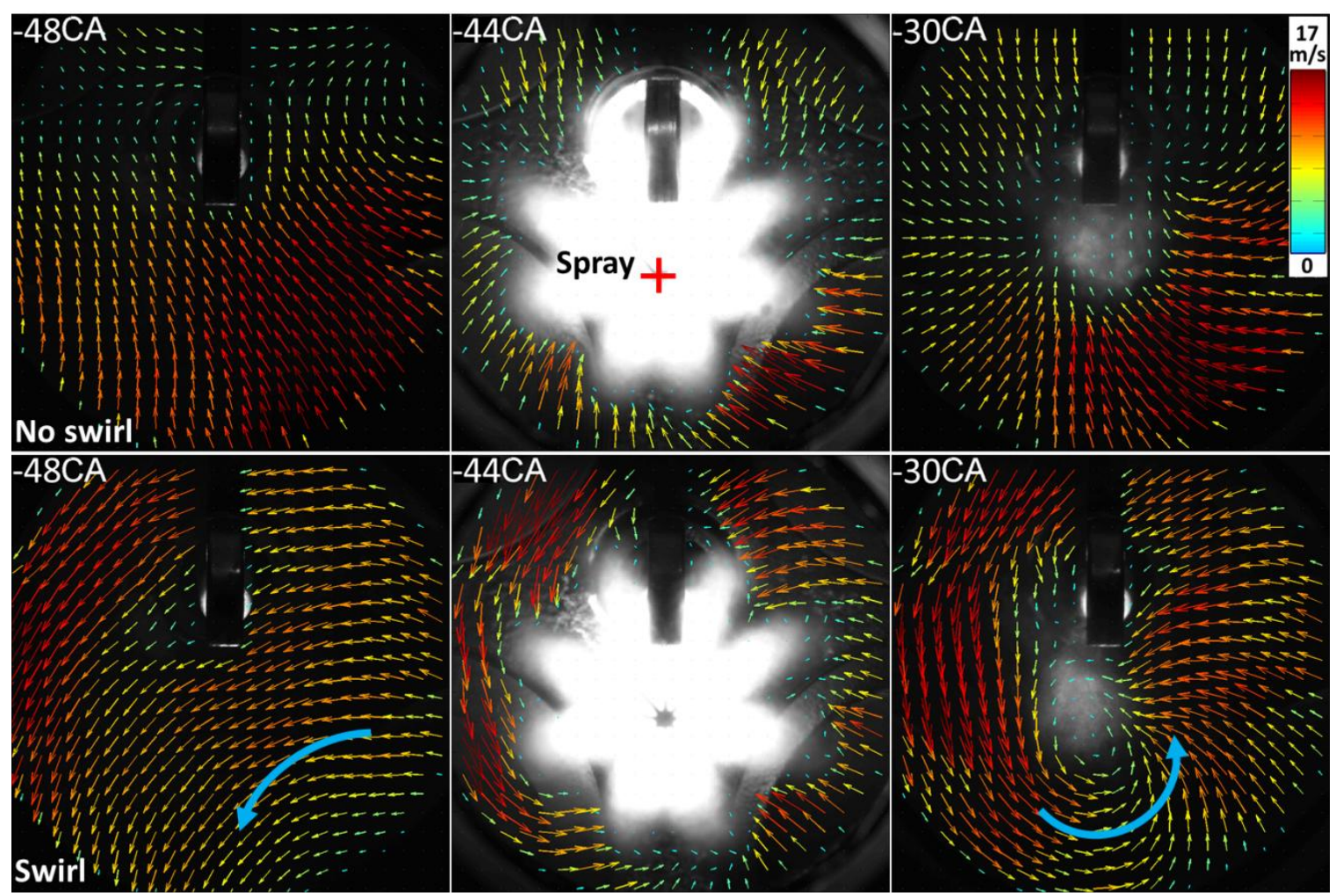

Fig. 11. Ensemble mean flow, and spray at $2000 \mathrm{rpm}$ for operation with and without swirl SOIa $=-47^{\circ} \mathrm{CA}$, EOIa $=-$ $34^{\circ} \mathrm{CA}, \mathrm{ST}=-35^{\circ} \mathrm{CA}$ (Tests 3 and 4 in Table 4 ). 


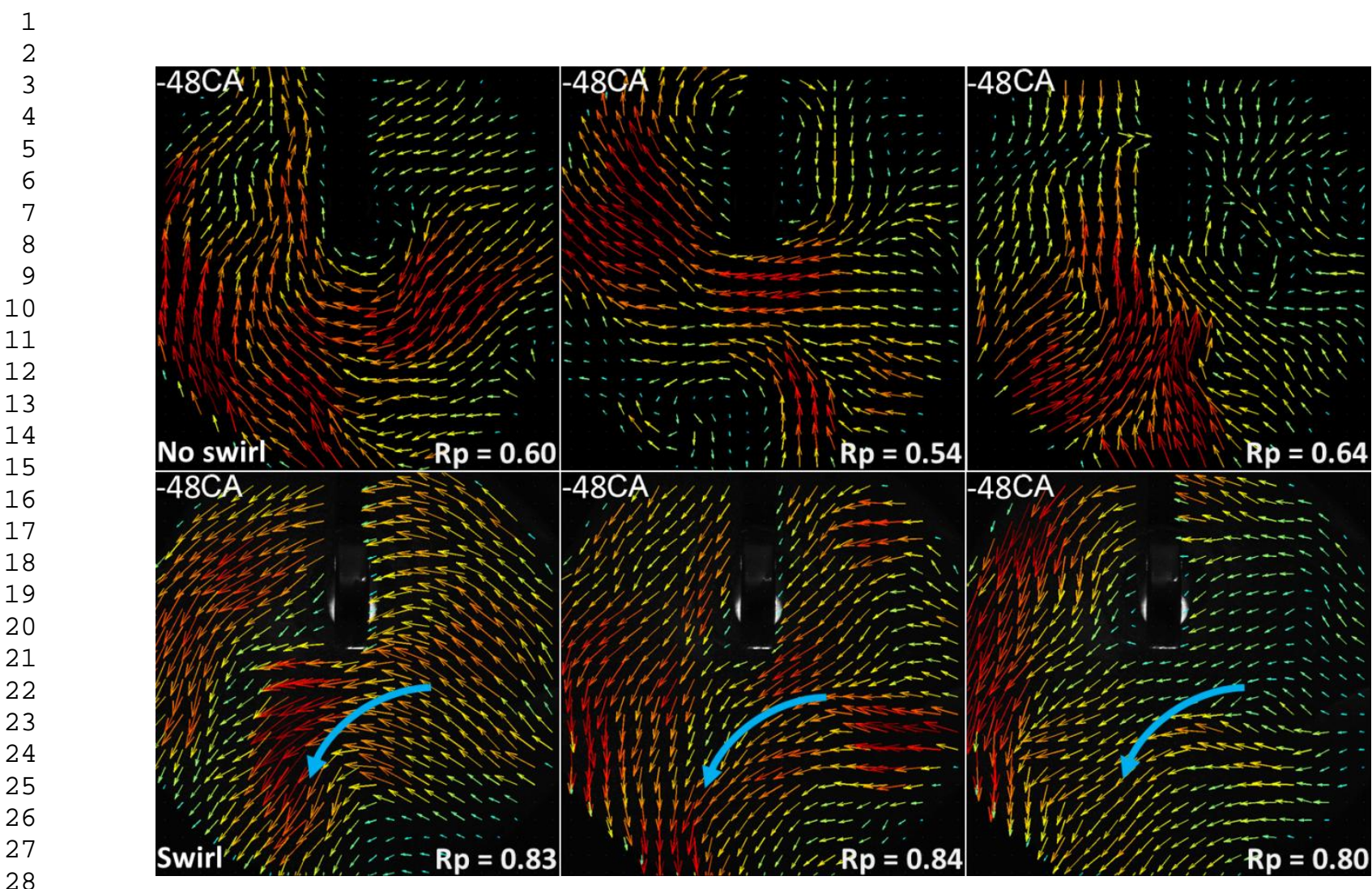

(a) Vector field before injection (at $-48^{\circ} \mathrm{CA}$ ATDC)

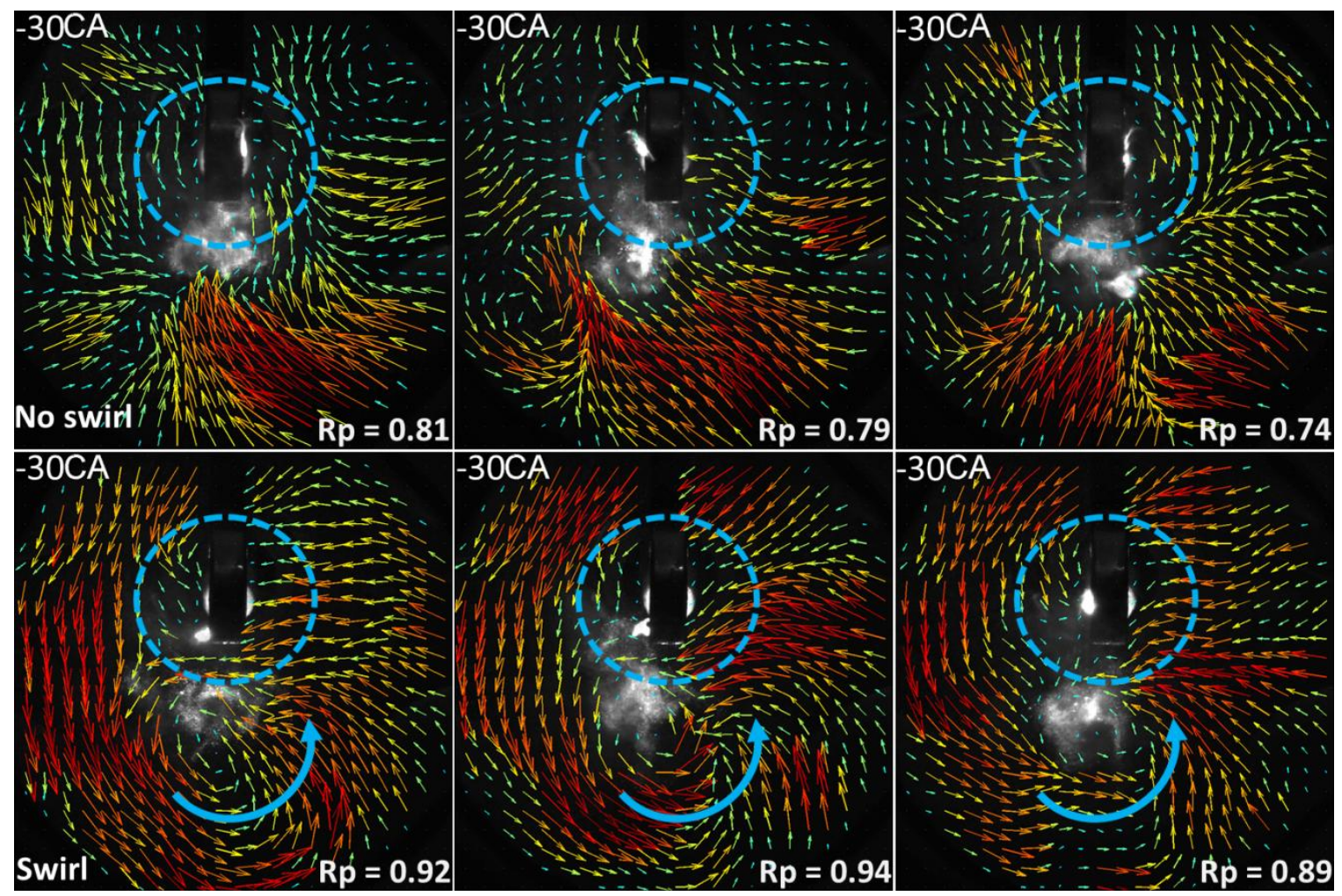

(b) Vector field after injection and during spark discharge $\left(-30^{\circ} \mathrm{CA}\right.$ ATDC). Dashed blue circles highlight the spark plasma with gas-flow around spark plug.

Fig. 12. Influence of swirl on cycle-to-cycle variations of the gas flow after injection and subsequent spark plasma motion. Three individual cycles selected from operation at $2000 \mathrm{rpm}$ with and without swirl $\left(\mathrm{SOI}_{\mathrm{a}}=-47^{\circ} \mathrm{CA}, \mathrm{ST}=-\right.$ $35^{\circ} \mathrm{CA}$, Tests 3 and 4 in Table 4). 
The reduced cycle-to-cycle variability of the local turbulent flow in this engine is characterized using root-mean-square (RMS) velocity fluctuation ${ }^{2}$ from ensemble average vector field. First the RMS velocity deviation from the ensemble average vector is calculated using Eqn. (1), from each measured 2-D velocity distribution of the $\mathrm{k}^{\text {th }}$ cycle for a total of $c=50$ cycles. The velocity magnitude at each grid location $\left(\vec{V}_{i, j, k}\right)$ is computed from the $x$ - and $y$-velocity components. $\vec{V}_{i, j, a v g}$ is the average velocity magnitude over all 50 cycles. The spatially averaged RMS velocity is then computed as Eqn. (2) where $n \times m$ is the size of PIV vector field. Here only active vectors (that are not disabled) are taken into account.

$V_{r m s}=\left(\left(\frac{1}{c}\right) \sum_{1}^{c}\left(\vec{V}_{i, j, k}-\vec{V}_{i, j, a v g}\right)^{2}\right)^{0.5}$

$\overline{V_{r m s}}=\frac{1}{n \times m} \sum_{1}^{n} \sum_{1}^{m}\left(V_{r m s}\right)$

Figure 13 presents the averaged vector field and the distribution of RMS velocity fluctuation during spark discharge for operation at both 1000 and $2000 \mathrm{rpm}$, with and without swirl. At $1000 \mathrm{rpm}$, the magnitude of RMS velocity is relatively small for operation both with and without swirl, but the operation with swirl shows slightly lower flow variations. Significant increase in flow variability $(\approx 2 x)$ is observed when increasing engine speed from 1000 to $2000 \mathrm{rpm}$ for operation without swirl, while creating a directed swirling flow efficiently reduces the magnitude of RMS velocity at $2000 \mathrm{rpm}$, indicating that the flow in each cycle is more similar to the ensemble mean. These observations are directionally consistent with the influences of intake-generated swirl and engine speed on $\mathrm{IMEP}_{\mathrm{g}}$ variations shown in Fig. 7. It is also noted for later use, that the RMS distribution at $2000 \mathrm{rpm}$ without swirl shows elevated variability in the lower right-hand corner.

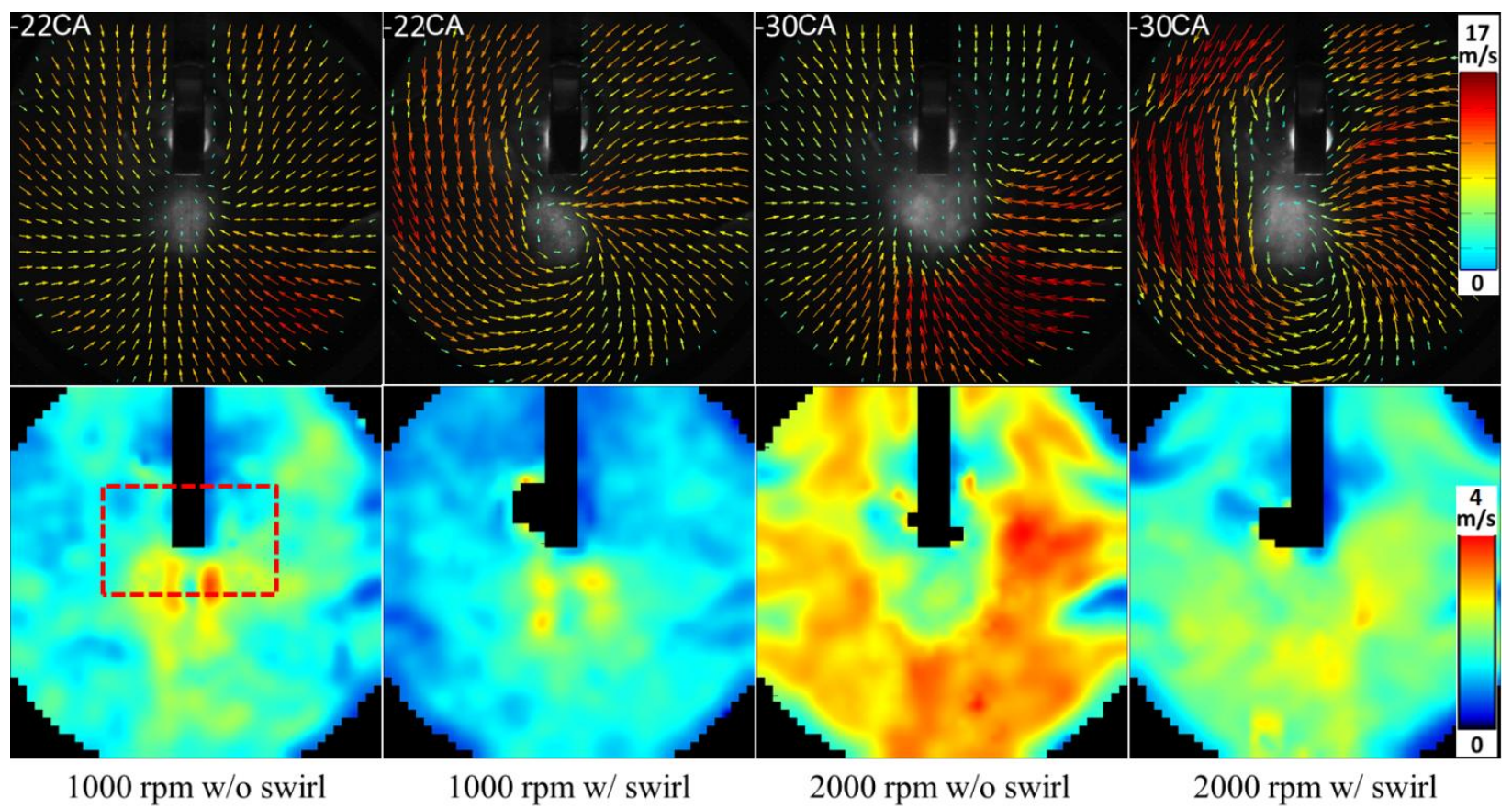

Fig. 13. Ensemble average flow field and the corresponding RMS velocity fluctuation from the ensemble mean; vector fields and RMS images obtained during spark discharge and after injection for Tests 1-4 shown in Table 4.

On a side note, it can be observed in Fig. 13 that some RMS data are missing near the spark plug. This occurs because during data processing a dynamic mask was used to exclude areas where spark plasma is

\footnotetext{
${ }^{2}$ The RMS results from both the cycle-to-cycle variability of the large-scale structures, which are the most energetic and thus dominate the RMS, as well as the less energetic small-scale dissipative structures.
} 

During ignition the camera is imaging the natural luminosity from the bright spark plasma. Since the time difference between two consecutive camera exposures is much longer than the time difference between two PIV-laser pulses, the PIV cross-correlation algorithm can produce much larger vectors for spark plasma, causing errors for the flow-field measurement. Therefore, the vectors located in the spark plasma are removed, resulting in disabled regions near the spark plug for RMS distribution.

The effect of the flow variability on the early flame period is quantified in Fig. 14. The red circles plot the spatial average of the local RMS velocity (Eqn. 2) versus the STD CA10 for all four PIV test conditions shown in Table 4 . The spatially averaged RMS velocity is computed in the vicinity of spark plug as indicated by the dashed red rectangle in Fig. 13, which will be shown later to be the region containing the spark-plasma convection and nascent flame kernels. The time-based STD CA10 values for the continuously fired metal-engine operation (Tests 1-4 in Table 3) are also shown in Fig. 14. The metalengine values are included because they have a larger sample size (500 cycles vs. 50 for the optical) and thus lower statistical error. Of course the RMS velocity could only be measured in the optical tests. However, the trends between the flow metrics and combustion performance shown in Fig. 14 for all-metal and optical results are similar. Thus, it is implicitly assumed that the replacement of the $\mathrm{O}_{2}$ with $\mathrm{N}_{2}$ has a negligible effect on the RMS velocity for the purpose of these estimates.

Figure 14 clearly demonstrates that an increase in the measured flow cyclic variability $\left(\mathrm{V}_{\mathrm{rms}}\right)$ near the spark plug results in an increased CA10 variability. Specifically, the use of swirl at 2000 rpm markedly decreases (improves) the early-burn variability. Furthermore, the spatially averaged value of RMS in the vicinity of the spark plug for $2000 \mathrm{rpm}$ with swirl is even smaller than that for $1000 \mathrm{rpm}$ without swirl, and corresponds to a lower value of STD CA10. Figure 14 provides the basis for developing a hypothesis: ignition and early flame kernel growth are less repeatable when cycle-to-cycle variation of the flow near the spark plug is larger. These intuitive insights provide additional motivation for the plasma and early flame imaging analysis in the following sections.

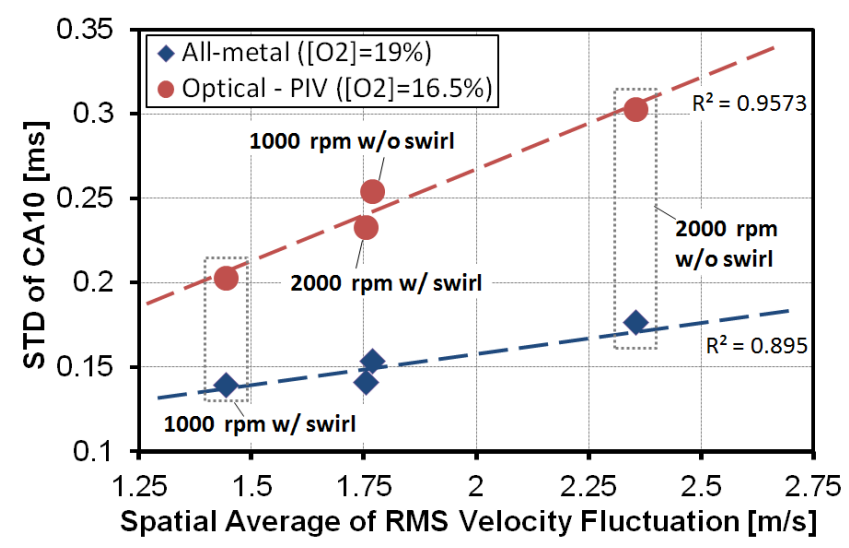

Fig. 14. Influence of intake-generated swirl and engine speed on changes of time-based CA10 deviation and spatial average of local RMS fluctuation from ensemble mean (Tests 1-4 in Table 4). The calculation of RMS is based on the region in the vicinity of the spark-plug as indicated in Fig. 13 with a dashed red rectangle. RMS data correspond to $-22^{\circ} \mathrm{CA}$ for $1000 \mathrm{rpm}$, and $-30^{\circ} \mathrm{CA}$ for $2000 \mathrm{rpm}$.

\subsection{Flow Variability and Spark Plasma Motion}

Previously, high-speed optical imaging has shown that, in spray-guided stratified-charge engines, the spark-plasma channel and early flame-kernel growth are highly dependent on local turbulent flow field 
[11]. The high-speed PIV results presented in Fig. 12b are based on images that also record the motion of the bright spark plasma. It is observed that the spark-plasma convection is controlled by cycle-to-cycle variations of the local flow, as highlighted by the dashed blue circles. It shows that for the operation without swirl flow, spark plasma can stretch to either the right or to the left side of the spark plug. By examining these vector fields, it can be seen that the spark-plasma motion highly depends on the direction and magnitude of the flow field around the spark plug. For example, the vector field in the blue circle of the top-middle image (no swirl) clearly shows that the spark plasma can be pushed out of the spark-plug gap by the flow on the right-hand side, since on the left-hand side, the magnitude of vectors is much smaller. Larger flow variations are observed for operation without swirl, especially for the flow field around the spark plug. Therefore, a more random spark-plasma motion is observed for operation without swirl. For operation with swirl, the more repeatable flow, with a better-centered and higher angularmomentum vortex, drives the plasma away from the spark plug and stretches the spark plasma in a more repeatable direction for all three individual cycles.

Figure 15 presents 2D-probability distributions from 50 cycles to quantify the spark-plasma location for operation at $2000 \mathrm{rpm}$ with and without swirl (Tests 3 and 4 in Table 4). With swirl, it is more probable that the plasma is convected toward the left-hand side of the spark plug, following the swirl-flow direction. Thus the spray-enhanced swirl flow typically stretches the spark plasma away from the spark plug toward the spray plume on the left side of the spark plug. Without swirl, the higher-probability regions are located closer to the spark plug but exist on both sides without any obvious asymmetry with respect to the spark plug. This indicates that the plasma is stretched to either of the two spray plumes that straddle the spark plug. These results show that the swirl-stabilized flow leads to a more consistent sparkplasma motion from cycle to cycle. This is likely an important aspect that contributes to the higher combustion stability for operation with swirl.

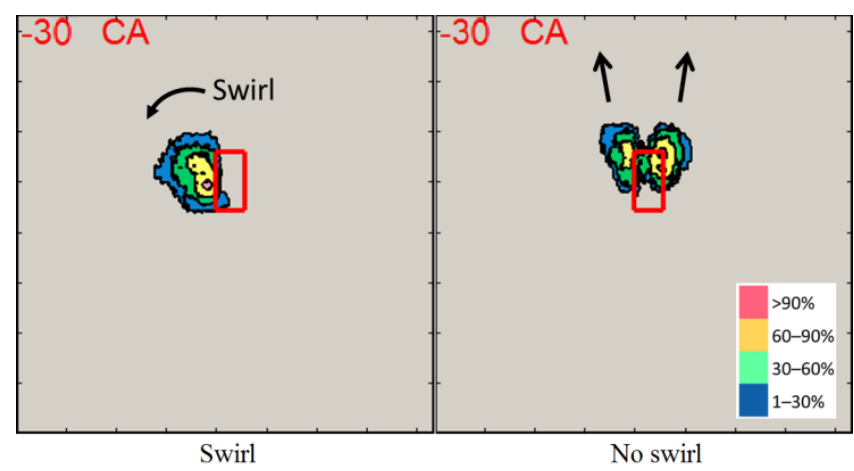

Fig. 15. Probability maps of spark plasma location for operation with and without swirl at $2000 \mathrm{rpm}$ (Tests 3 and 4 in Table 4)

On a final note, the arrows in the no-swirl 2D-map in Fig. 15 indicate how the flow affects the plasmastretch direction. The arrows also indicate the expected propagation of the early ignition kernels, as viewed via the piston-bowl window. In addition, the flame kernels are expected to travel downwards (out of the page), following the wake of the fuel sprays for operation both with and without swirl [16].

\subsection{Early Flame Kernel Growth}

Flame imaging is required during early flame growth period since pressure-based AHRR analysis is not sufficiently precise prior to CA04. Figure 16 shows the relationship between CA04 from the AHRR and 
projected flame area at $-26^{\circ} \mathrm{CA}$ ATDC. At $-26^{\circ} \mathrm{CA}$, the MFB $<1.5 \%$ is found for all cycles. The red circles demonstrate that with swirl, all cycles have a flame area greater than $3 \mathrm{~mm}^{2}$. Also, analysis of the data shows that the cycle-averaged area is greater than that of operation without swirl. Without swirl (diamonds), the flame-area distribution has a wider range, and many cycles show a flame area below 3 $\mathrm{mm}^{2}$. The blue diamonds indicate poor-burn cycles with FMFB $<92 \%$. These demonstrate that having a small flame area increases the risk of a low FMFB cycle. However, the correlation is weak and some poor-burn cycles have average flame area and CA04. The combustion process of these poor-burn cycles that start out well must therefore deteriorate sometime after CA04.

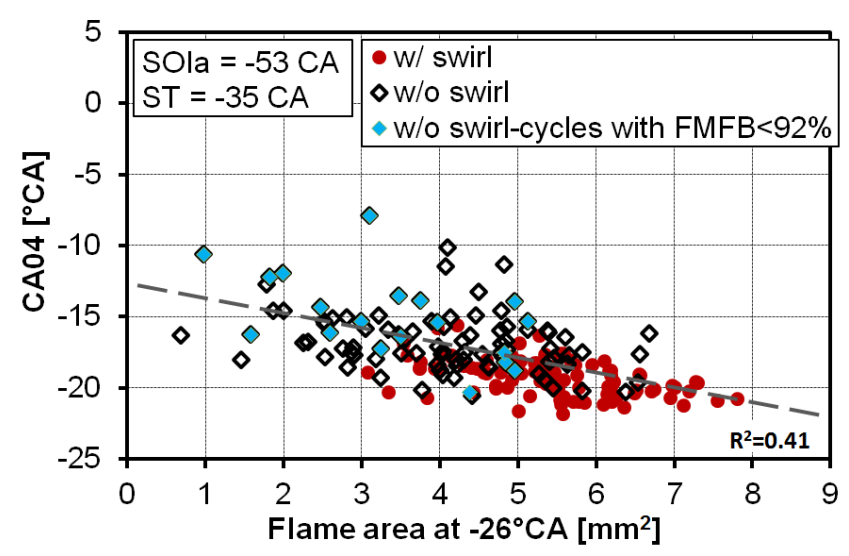

Fig. 16. Correlations between early flame area and CA04 for operation with and without swirl at $2000 \mathrm{rpm}$ (Tests 3 and 4 in Table 2, optical operation for flame imaging). The flame imaging data at $-26^{\circ} \mathrm{CA}$ ATDC, correspond to MFB $\leq 1.5 \%$.

\subsection{Flame Imaging - Early Flame Kernel Growth and Subsequent Flame Propagation}

Here, the flame imaging of the early kernel and flame propagation is analyzed together with the pressurebased AHRR. It should be noted that the late period of the combustion cannot be distinguished from the early-burn products (in this view) and may in fact be outside the field of view, i.e. outside the piston bowl. The high-swirl results are presented first to demonstrate AHRR and early flame development of good-burn cycles. This sets a standard against which the no-swirl results can be compared to demonstrate properties of poor-burn cycles. Conditional sampling is used to illustrate early and late burn issues.

\subsubsection{Classification of flame propagation using conditional analysis}

Here, analysis is focused on cycles from flame imaging Tests 5 and 6 (see Table 3), where ST is one degree delayed from the best ST operation (Tests 3 and 4) to create more poor-burn cycles. Figure 17 presents CA10 variations with cycle number sorted by CA10 (as per Fig. 10) and with the partial-burn cycles highlighted. For operation with swirl, all cycles have a FMFB above 92\%. For operation without swirl, 7 out of 12 partial-burn cycles $(\mathrm{FMFB}<90 \%)$ have a CA10 later than $-12^{\circ} \mathrm{CA}$, indicating a slow early burn. This trend is the same as all-metal engine results shown in Fig. 10, with late-CA10 cycles having a higher risk of turning into partial burns. However, it can be seen that cycles with a relatively fast early burn (early CA10) can develop into a partial burn too. 
Fig. 17. Cycle-to-cycle variations of CA10 and CA10 regions for different categories of flame propagation shown in Table 5 (flame imaging data)

To investigate causes of poor early flame-kernel development versus poor late burning, CA10 and FMFB are used to conditionally sample cycles based on the five categories in Table 5. Poor burns are defined as FMFB $<92 \%$, and normal burns get FMFB $>92 \%$, where FMFB was shown to correlate well with IMEP $_{\mathrm{g}}$ in Fig. 8. The categories are listed in Table 5 and highlighted in Fig. 17. Type A includes 10 cycles from operation with swirl and all cycles for this type show a relatively fast early burn (CA10 < $13^{\circ} \mathrm{CA}$ ) and a relatively complete final combustion (FMFB < $92 \%$ ). Types B-E are for operation without swirl. Cycles for both types $\mathrm{B}$ and $\mathrm{C}$ have a relatively fast early combustion (CA10 $<-13^{\circ} \mathrm{CA}$ ), but all cycles of type C develop into a relatively poor burn (FMFB < 92\%). 10 cycles are selected for type B and these cycles have a CA10 range similar to type A. 7 out of 100 cycles are found for type C. Cycles for types $\mathrm{D}$ and $\mathrm{E}$ have a slow early burn $\left(\mathrm{CA} 10<-12^{\circ} \mathrm{CA}\right)$, but all cycles of type $\mathrm{E}$ ( 8 cycles in total) finally have a relatively complete combustion (FMFB $>92 \%)$.

Table 5. Classification of flame propagation for conditional analysis

\begin{tabular}{|c|c|c|c|c|c|}
\hline Type & Swirl & Test & CA10 $\left({ }^{\circ} \mathrm{CA}\right)$ & FMFB (\%) & Sample size \\
\hline A & Yes & 5 & $<-13$ (Normal) & $>92$ (Normal) & 10 \\
\hline B & No & 6 & $<-13$ (Normal) & $>92$ (Normal) & 10 \\
\hline C & No & 6 & $<-13$ (Normal) & $<92$ (Poor) & 7 \\
\hline D & No & 6 & $>-12$ (Poor) & $<92$ (Poor) & 7 \\
\hline$E$ & No & 6 & $>-12$ (Poor) & $>92$ (Normal) & 7 \\
\hline
\end{tabular}

\subsubsection{Flame propagation for good-burn cycles, with swirl}

Figure 18 presents the AHRR and imaging analyses for operation with swirl at $2000 \mathrm{rpm}$. Similar to the metal-engine results shown in Fig. 10, here all cycles have a FMFB above 92\%. These are presented first to demonstrate the AHRR variability present for high-swirl operation. The 10 cycles highlighted in blue (Type A) represent a range from about the average cycle to the most poorly burning cycles (still with FMFB > 92\%). Compared to the faster-burning cycles (higher and earlier AHHR), some of these "blue" cycles either started slower with a single peak while others apparently began slow but recovered (doublepeak AHHR); regardless, since all attained FMFB > 92\%, the cycles recovered sufficiently fast. With a 
few exceptions (with this engine and operating condition), the cycles did not exhibit the distinctive twostage burning observed by Drake, et. al.[24].

In the images here and that follow, the RGB color-matrix and white-balance for individual flame images were altered to enhance the display of the weak blue early flames. Therefore, the display of flames during later mixing-controlled combustion of rich products tends to be saturated, especially for good-burn cycles with soot luminosity. It needs be noted that the $\mathrm{CO} *$ continuum (blue) in rich regions of $\mathrm{CO} \rightarrow \mathrm{CO}_{2}$ burning cannot be unambiguously distinguished from $\mathrm{CH}^{*}$ in premixed burning. All the flame-location PDFs below were created by thresholding the blue channel in each pixel. The threshold value was chosen to be 100 out of a total image intensity depth of 4095. This threshold is based on empirical observation and makes the PDFs reflect the statistical location of both the weaker blue flame along with the higher intensity regions. Also, images are shown only up through TDC, since the flames filled the field of view (FOV) after TDC, making those later images not instructive.
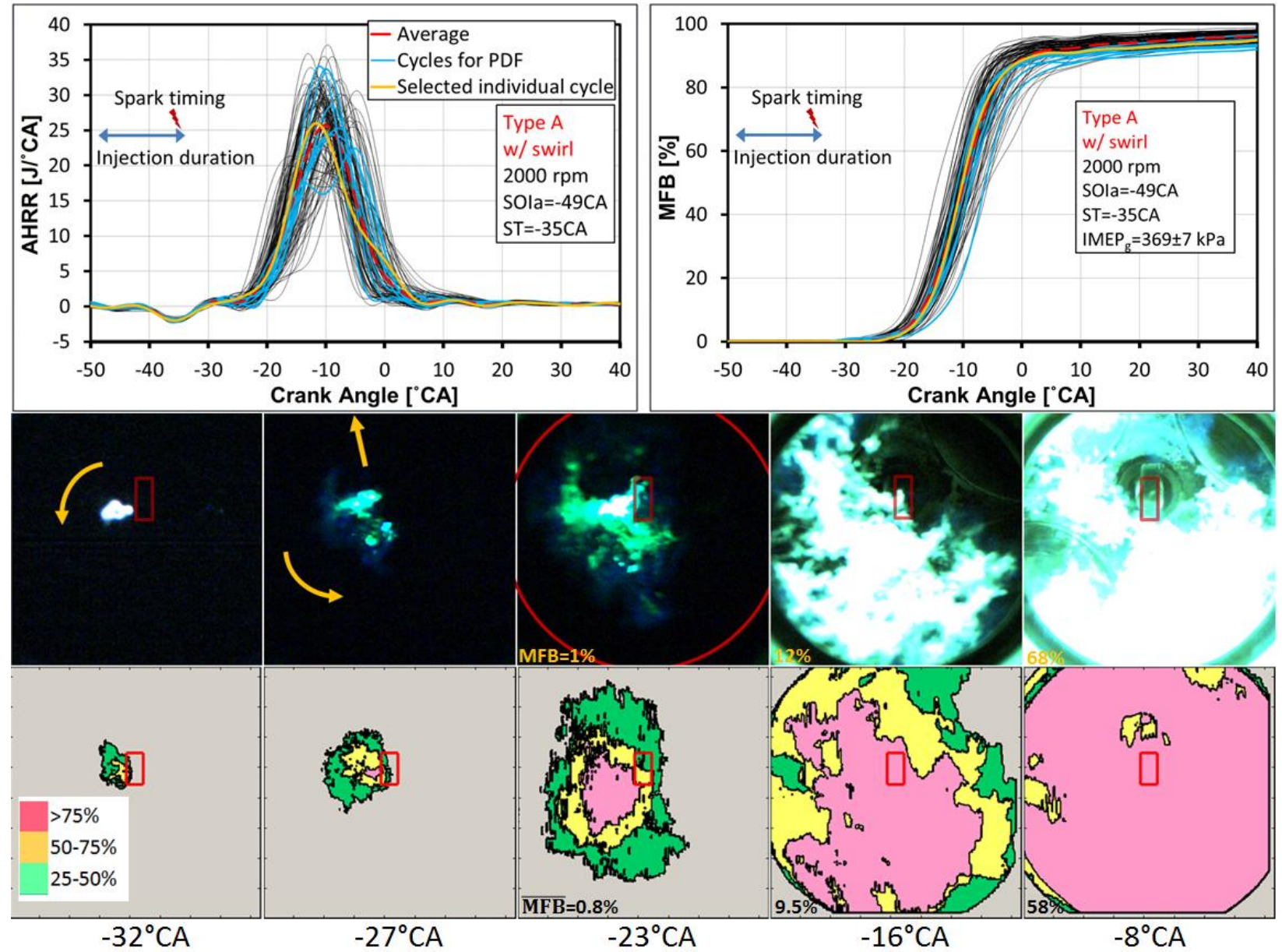

Fig. 18. Type A (normal CA10, Normal FMBF, with swirl, 2000rpm) individual-cycle apparent heat-release analysis at $2000 \mathrm{rpm}$. Blue cycles highlight the range of cycles discussed in the text. The cycle highlighted in yellow corresponds to the single-cycle images (top row). The lower row is the flame probability map for the 10 blue highlighted cycles.

The top row of the images in Fig. 18 is from the individual AHRR cycle highlighted in yellow, which is close to the average AHRR. Consistent with the velocity and plasma measurements, the spray-enhanced swirl flow pushes the spark plasma away from the spark gap at $-32^{\circ} \mathrm{CA}$ ATDC. This ignites fuel-air mixtures on the left-hand side of the spark plug, thereby quickly establishing the early flame kernel, as demonstrated at $-27^{\circ} \mathrm{CA}$ ATDC. Further, the established early flame kernel propagates into the bowl 
through two directions, as indicated by the yellow arrows. This drives the bulk of early flame to ignite the spray plumes in the 6-9 o'clock directions while some of the early flame still propagates along the spray plume next to the spark plug in the 11 o'clock direction. Finally, the luminous flame fills the FOV by $8^{\circ} \mathrm{CA}$ ATDC. The lower row in Fig. 18 shows the PDF of the flame location for the 10 blue cycles. A comparison of the two rows reveals consistency between the observations noted for the single yellow cycle and the flame statistics for all 10 blue cycles. These flame-spread observations are significantly different from that of no-swirl operation shown next.

\subsubsection{Flame propagation for operation without swirl}

Figure 19 shows AHRR for 100 cycles for operation without swirl at $2000 \mathrm{rpm}$. The 10 cycles highlighted in blue were selected to represent the Type B cycles, which have normal CA10, normal FMFB, and are used to create the probability map in Fig. 19.
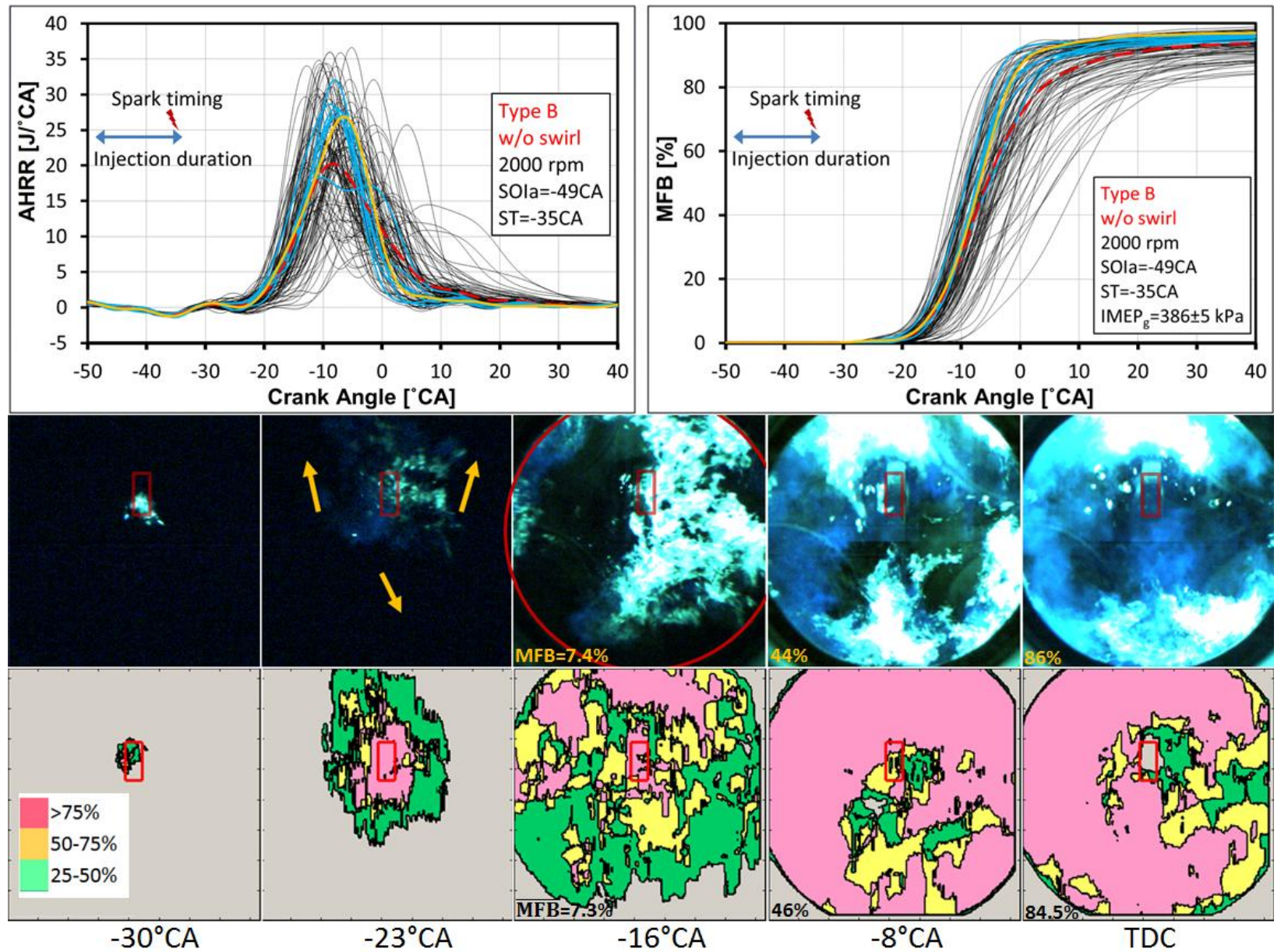

Fig. 19. Individual-cycle apparent heat-release analysis for $2000 \mathrm{rpm}$ without swirl. Blue cycles highlight the Type B cycles, normal CA10, normal FMFB. The cycle highlighted in yellow corresponds to the single-cycle images (top row). The lower row is the flame probability map for the 10 Type B (blue) cycles.

Comparing the MFB curves of Figs. 18 and 19 demonstrates that normal cycles without swirl have as early CA10 as the fastest high-swirl cycles. Most of the Type B cycles burn well throughout. However, two of the cycles began to slow but recovered (showing the two-stage AHHR [24]), with all 10 cycles 
attaining FMFB $>92 \%$. The single cycle does not show the same swirl-affected flame spread as Type A. Instead, later combustion in the $45 \%-85 \%$ MFB range ( $-8^{\circ}$ to TDC) displays highest flame intensity at the top and bottom of the FOV. Comparing the flame PDFs at $-23^{\circ} \mathrm{CA}$ (with and without swirl) demonstrates that they are nearly equivalent in size, but that the PDF of Type B is not shifted leftward like it is for the swirl case in Fig. 18. Judging from a comparison of the PDFs at $-16^{\circ} \mathrm{CA}$, the flame spread is substantially more random and/or slower for the non-swirl case.

Figure 20 presents the analysis of Type $\mathrm{C}$ at $2000 \mathrm{rpm}$ without swirl, for which the cycles start burning well (normal CA10) but fail to achieve a high FMFB. The AHRR demonstrates that combustion is robust at the beginning but then falls off and does not recover sufficiently. The probability maps and individual flame images shown in Fig. 20 substantiate the AHRR measures. At $-23^{\circ} \mathrm{CA}$ both the individual cycle and the PDF show that the flame is about the same size as for the Type B cycles shown in Fig. 19. On the

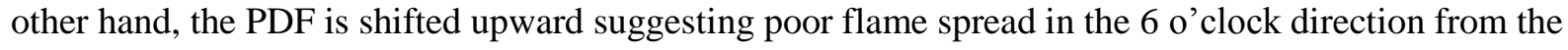
spark plug. This tendency of the poor FMFB cycles becomes stronger at $-16^{\circ} \mathrm{CA}(\cong 10 \% \mathrm{MFB})$ and the lack of flame spread in the $6 \mathrm{o}^{\prime}$ clock direction is clearly evident at $-8^{\circ} \mathrm{CA}$ and later ( $\left.\cong 40 \% \mathrm{MFB}\right)$.
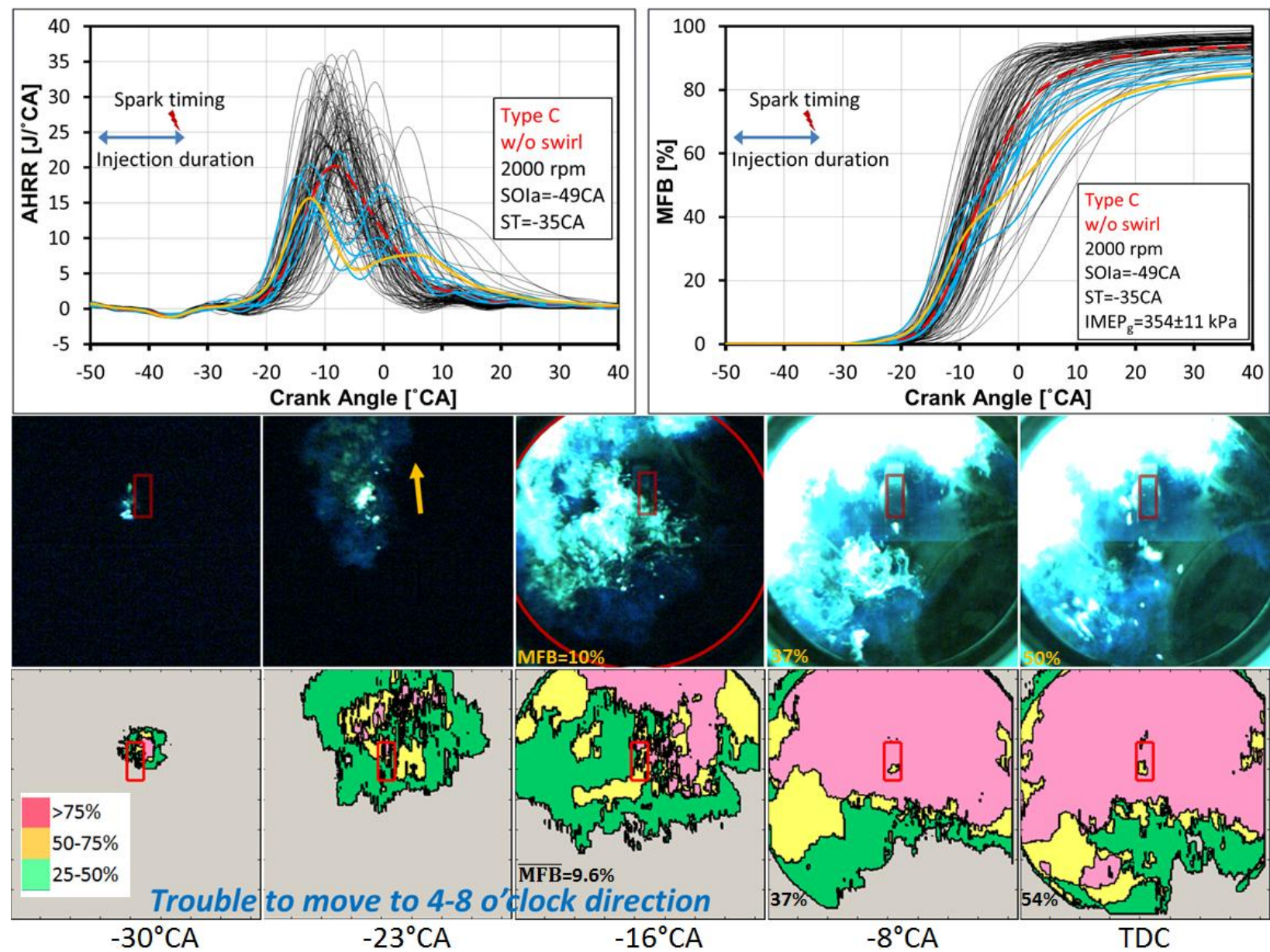

$\overline{\mathrm{MFB}}=\mathbf{9 . 6 \%}$ $-30^{\circ} \mathrm{CA}$ $-23^{\circ} \mathrm{CA}$ $-16^{\circ} \mathrm{CA}$

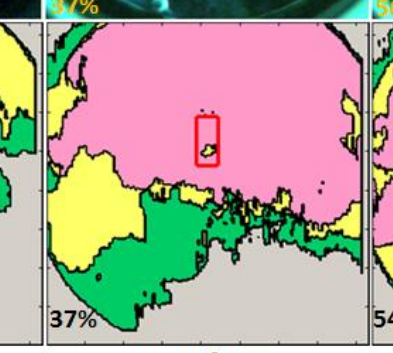

Fig. 20. Individual-cycle apparent heat-release analysis for $2000 \mathrm{rpm}$ without swirl. Blue cycles highlight the Type $\mathrm{C}$ cycles, normal CA10, poor FMFB. The cycle highlighted in yellow corresponds to the single-cycle images (top row). The lower row is the flame probability map for the 7 Type $\mathrm{C}$ (blue) cycles. 
Figures 21 and 22 present the analysis for Types D and E at 2000 rpm without swirl, respectively. For Fig. 21, cycles start burning poorly (late CA10) and do not recover, thus failing to achieve a high FMFB. Here cycles with the distinctive two-stage AHHR are more evident. The AHRR demonstrates that indeed early combustion is quite slow, and continues slow after TDC. Conversely, the blue cycles shown in Fig. 22 also start burning poorly (late CA10) but recover to achieve a high FMFB. This is clearly reflected when comparing the MFB and AHRR curves of Types D and E. The images of the single cycles (yellow MFB and AHRR) for both Types D and $\mathrm{E}$ do not achieve substantial burning until $-8^{\circ} \mathrm{CA}$, which is much later than for Type B flames. A comparison of the individual images and PDFs in Figs. 21 and 22 demonstrates that the recovered Type E cycles have a reasonably consistent flame propagation in the 6 o'clock direction whereas the non-recovering Type D cycles do not. As a result, the PDF for Type E fills the FOV at TDC with a MFB $=49 \%$. In this sense, it is comparable to the PDF for Type B at $-8^{\circ} \mathrm{CA}$, with a MFB $=46 \%$. In contrast, the PDF for Type D is still biased to its upper region at TDC, with a lower MFB of $42 \%$. These observations for no-swirl operation suggest that having flame propagation in the 6 o'clock direction is important to ensure that the mid-to-late combustion progresses well despite a slow early burn.
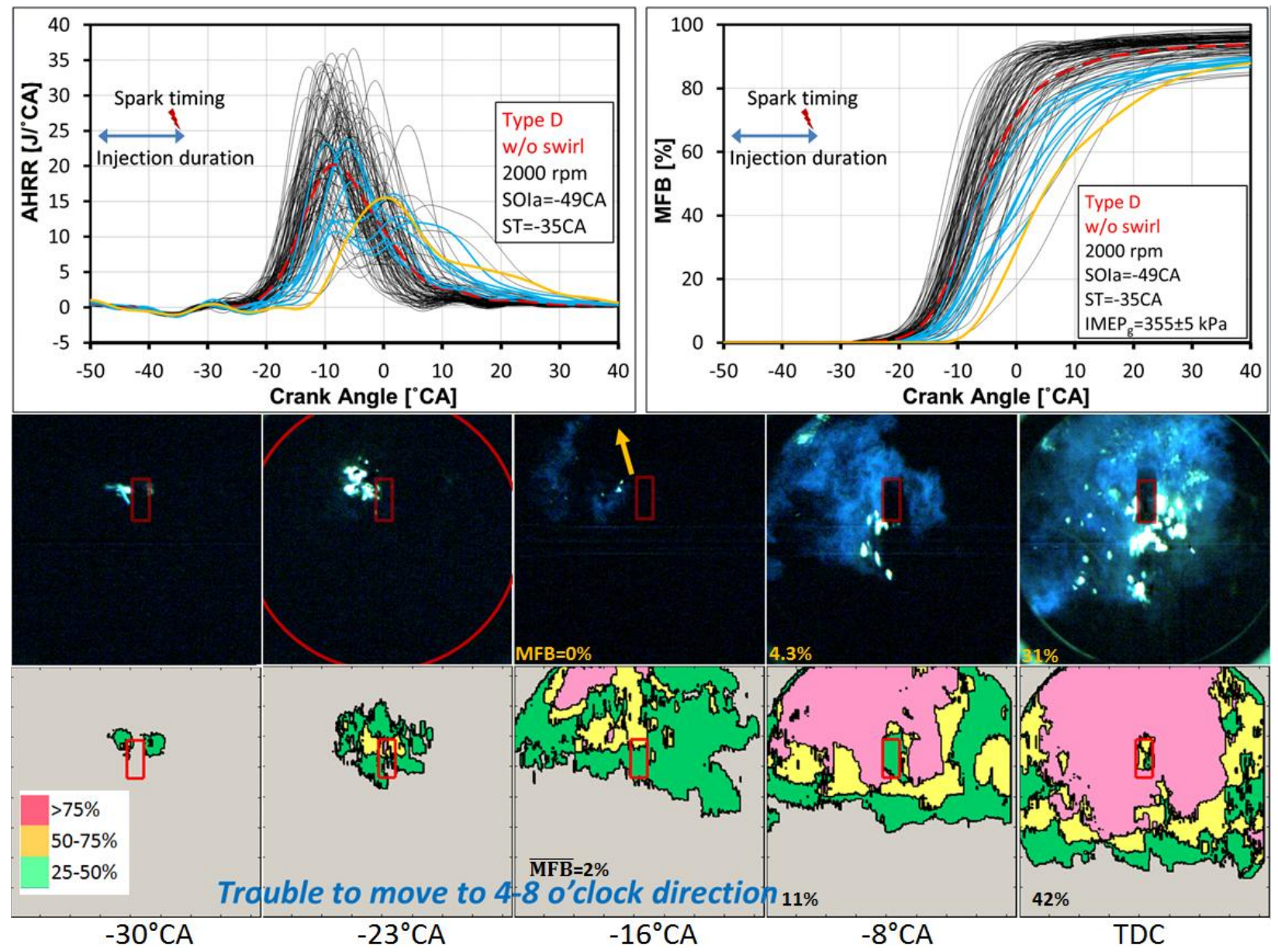

Fig. 21. Type D individual-cycle apparent heat-release analysis for $2000 \mathrm{rpm}$ without swirl. Blue cycles highlight the Type D cycles, poor CA10, poor FMFB. The cycle highlighted in yellow corresponds to the single-cycle images (top row). The lower row is the flame probability map for the 7 Type $\mathrm{D}$ (blue) cycles. 

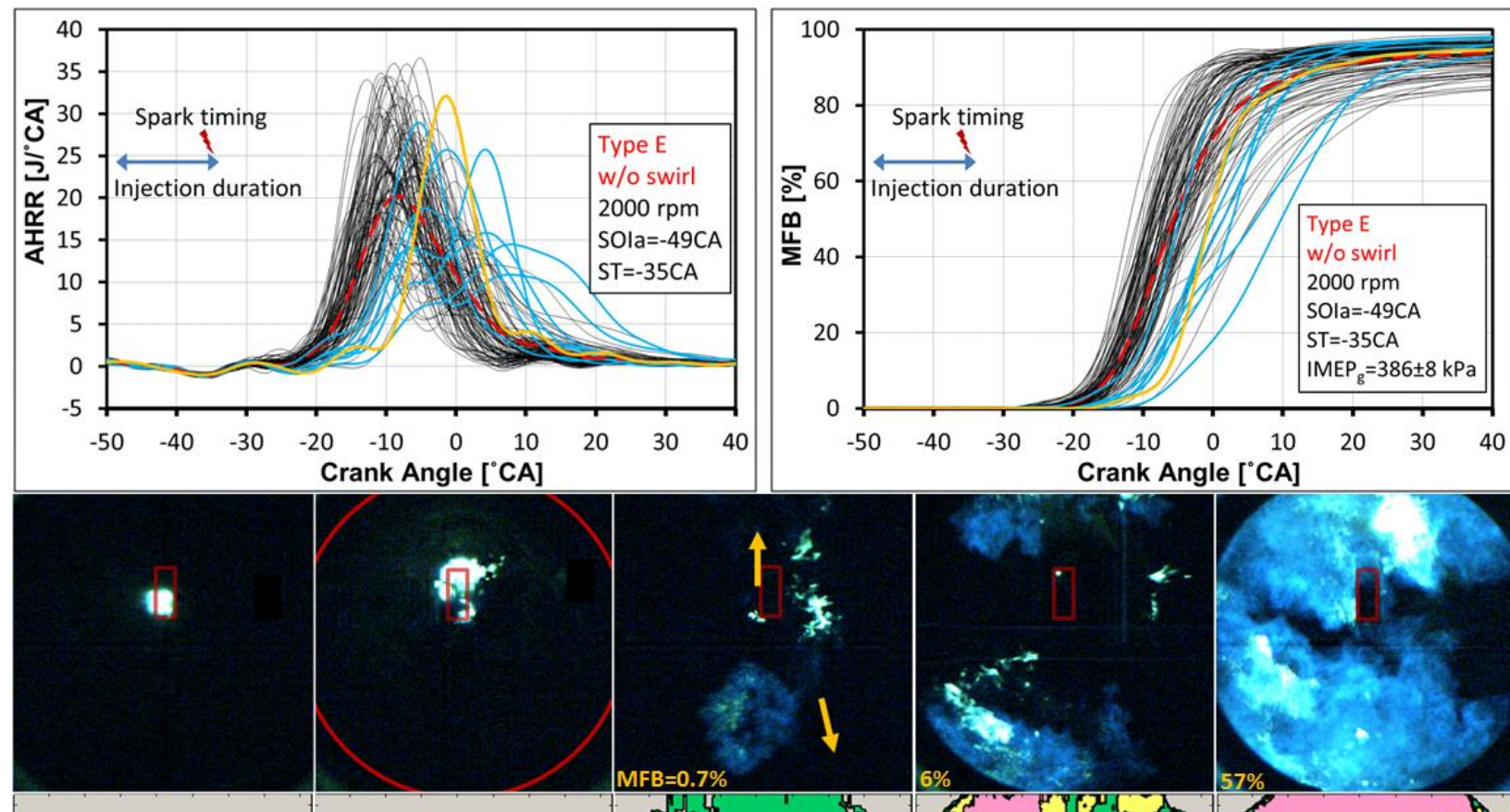

Crank Angle $\left[{ }^{\circ} \mathrm{CA}\right]$

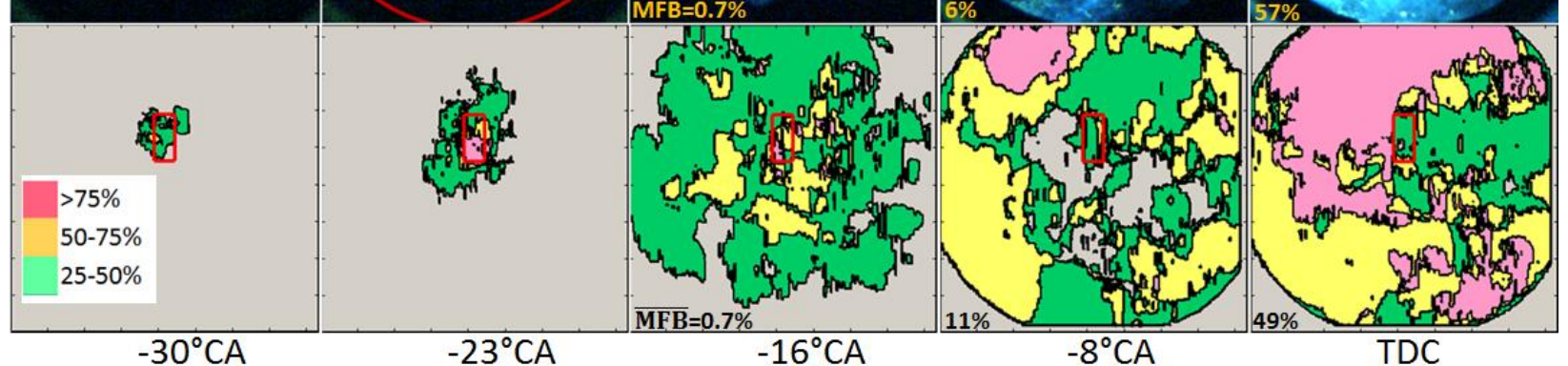

Fig. 22. Individual-cycle apparent heat-release analysis for $2000 \mathrm{rpm}$ without swirl. Blue cycles highlight the Type E cycles, poor CA10, normal FMFB. The cycle highlighted in yellow corresponds to the single-cycle images (top row). The lower row is the flame probability map for the 7 Type $\mathrm{E}$ (blue) cycles.

\subsection{Discussion}

The motivation throughout this study is to identify how swirl improves SG SC SIDI engine operation by suppressing poor and partial-burn cycles. The pressure analysis in Figure 7 demonstrates that cycle-tocycle variations become unacceptable (COV IMEP $=2.8 \%)$ at $2000 \mathrm{rpm}$ without swirl, but poor and partial burn cycles are largely corrected (COV IMEP $=1.4 \%)$ when swirl is applied. The continuous thread throughout the many measurements made in this study is that both variability and interruption of the late burn are responsible for the poor and partial-burn cycles.

The lack of correlation with combustion phasing and linear correlation of FMFB and IMEP in Figs. 8a \& $8 \mathrm{~b}$ demonstrates that incomplete combustion (low FMFB), rather than combustion phasing, contributes strongly to the low-IMEP cycles at this operating condition. Further, the relationship between CA90 and $\mathrm{IMEP}_{\mathrm{g}}$ in Fig. $9 \mathrm{~b}$ demonstrates that low-IMEP $\mathrm{g}_{\mathrm{g}}$ cycles universally have a delayed final combustion phase. Figure $9 \mathrm{c}$ demonstrates that there is indeed a relatively good linear correlation between the early-growth period (CA04) and the mid-burn milestones (CA10, CA30 and CA50). More importantly, the scatter plots show, and the $\mathrm{R}^{2}$ numbers quantify, the increased statistical variation (cycle-to-cycle variability) later in the burn. Thus, Fig. 9 shows that even if the variability of the early flame kernel growth were removed, poor and partial-burn cycles can result for operation without swirl. Later in the study, the 
AHRR plots in Figs. 20 and 22 demonstrate that cycles with good early burn can deteriorate, and that cycles with poor early burn can recover to complete the combustion process. The CFD simulations of Drake, et al [24] explain this distinctive two-stage AHHR as the result of partially-premixed burning followed by diffusion-dominated combustion of rich products. Following this logic, the predominately single-stage burning (observed for most cycles with this engine and operating condition) suggests that the poorly burning cycles are a result of the slower mixing dominated combustion later in the cycle.

The importance of the ignition and early flame kernel growth period was reviewed recently [5]; it is the period between the start of ignition, ST, and the time when a fully developed turbulent flame is sufficiently robust to be captured by pressure-based heat-release analysis, here defined as CA04. Of course, cycle-to-cycle variability of the ST-to-CA04 delay imposes phase variations, and is conceptually equivalent to ST variations with a fixed ST-to-CA04 delay. As a result, the cycle-to-cycle variability of both the early flame kernel causes the flame during the main portion of the burn (CA04 to CA at FMFB) to experience differences in thermodynamic state $(\mathrm{T}, \mathrm{P})$, turbulent flow, degree of fuel-air mixing, and piston-bowl inflow/outflow. An increase in the early flame growth period clearly increases the probability of poor burns as shown in Figs. $9 \& 10$; but is neither a necessary nor a sufficient condition to predict poor/partial burns since early CA10 cycles can fail and late CA10 cycles can recover (Figs. $10 \& 17$ ).

It is important to note that for these operating conditions the combustion phasing is early. This is shown by the fact that all normal-burn cycles have a CA50 before TDC and many have a CA90 before TDC. The AHRR curves of Figs. 18 through 22 show that both normal and poor-burn cycles can be interrupted prior to TDC (with and without swirl) and may or may not recover. The burning of interrupted cycles is shown to extend well into the expansion stroke. In fact, peak AHRR of a recovering cycle often occurs after TDC. These observations of the AHRR suggest that the interruption is not due to unfavorable thermodynamic state since both pressure and temperature are increasing due to piston and combustion compression of the unburned gases and that the interrupted burning rates are not always related to late phasing.

The optical diagnostics applied here clarify how swirl improves the combustion repeatability from cycle to cycle. Velocity measurements just above the piston bowl at TDC confirm that measurements made with motored flow [27] remain valid under fired conditions until early flame-formation period. In addition, Fig. 14 demonstrates that STD CA04 scales with the magnitude of cycle-to-cycle velocity variability (RMS velocity) near the spark plug for changes of engine speed and swirl. It is interesting to note from Fig. 13 that the largest $\mathrm{V}_{\mathrm{rms}}$ occurs for $2000 \mathrm{rpm}$ without swirl and in the same spatial region (6 o'clock) into which the flames do not propagate for the poor-burn cycles (Types C \& D).

Figure 15 shows PDFs of the spark-plasma location for operation with and without swirl. The nonswirling flow convects the plasma toward either of the spray plumes that straddle the spark-plug gap. In comparison, the swirl always convects the spark plasma counterclockwise toward the left spray plume, and thus is more repeatable from cycle to cycle. This of course is expected from the velocity measurements shown in Figs. $11 \& 12$, where the swirl center is below the spark plug, and thus has a strong flow towards the left at the spark plug.

Images and PDFs of the early flame $\left(\mathrm{CA} \leq-23^{\circ}\right)$ in Fig. 18, show that the flame propagates counterclockwise, following the direction established by the measured swirl flow. Figures 19 through 22 show that without swirl the early flame propagates either left or right and upward, causing the PDFs to be more symmetric about the spark plug. In addition, Fig. 16 demonstrates that, without swirl, the flame area at $-26^{\circ} \mathrm{CA}(\mathrm{MFB} \leq 1.5 \%)$ is statistically smaller than with swirl. Nonetheless, the early-kernel size 
alone is not a predictor of the poor or partial-burn cycles, again pointing to the importance of avoiding flame propagation failures during the later part of the combustion.

\subsection{Conceptual Descriptions of Flame-Propagation Types}

The AHRR and MFB plots in Figs. 18 through 22 clearly demonstrate that the AHRR of any cycle can be interrupted prior to TDC and may or may not recover, causing a poor-burn cycle. This cannot be fully explained using thermodynamic analysis. The flame images and PDFs in Figs. 18 to 22 demonstrate that the flame-spread direction is the principal factor that determines both burning-rate interruption after early burn and recovery during later combustion. Figure 23 replots the AHRR curves of the statistically selected individual cycles shown in Figs. 18 to 22 (yellow curves). Correspondingly, Fig. 24 provides a conceptual model to summarize these flame propagation types.

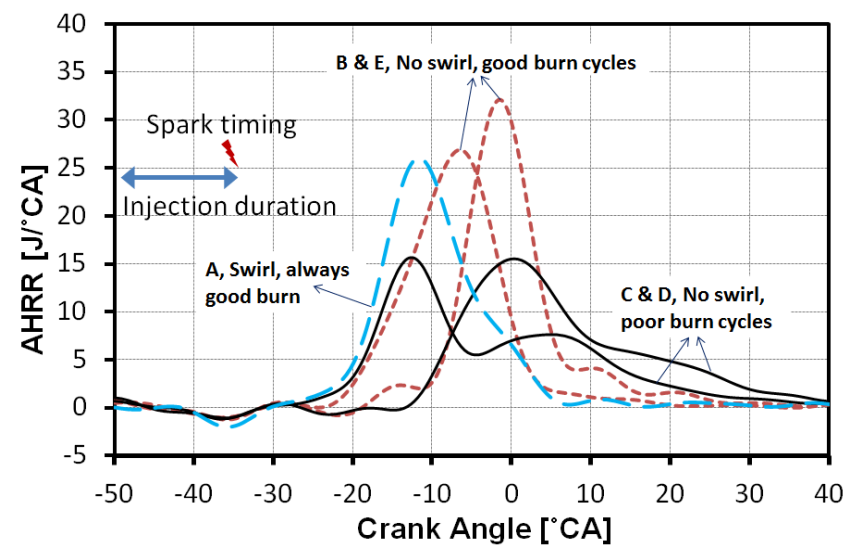

Fig. 23. AHRR curves of the selected individual cycles shown in Figs. 18 to 22 (yellow curves)

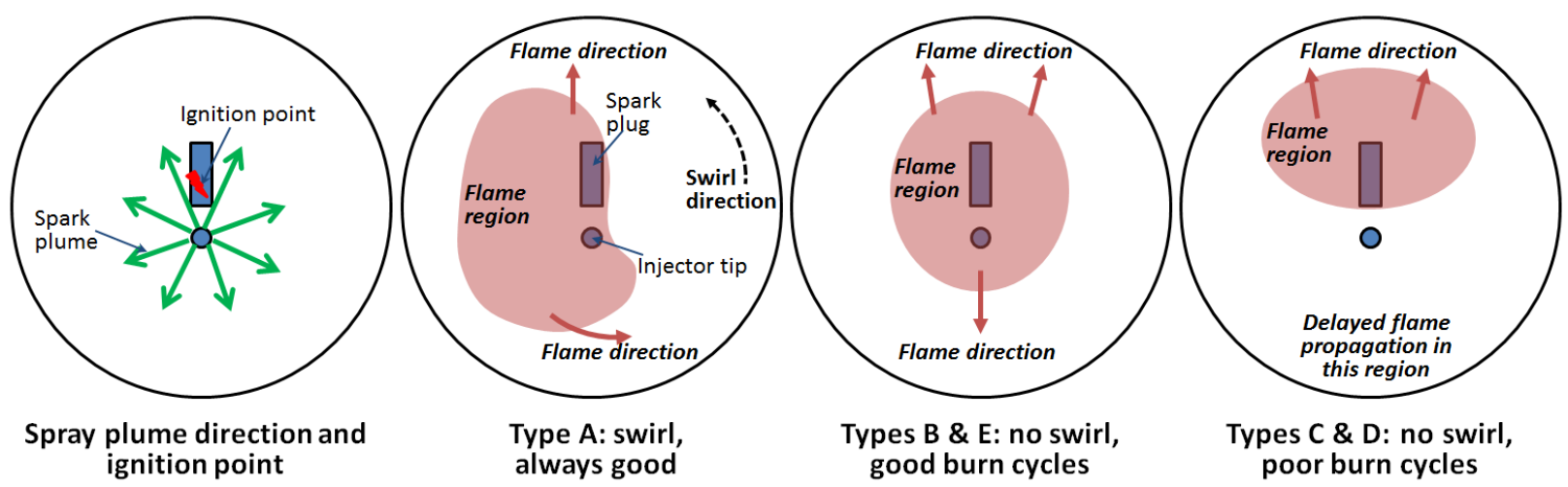

Fig. 24. Conceptual model of flame propagation with and without swirl

Without swirl, the images and PDFs in Figs. 19 and 22 (summarized for Types B \& E in Fig. 24) indicate that good-burn cycles have flame propagation in the 6 o'clock direction, regardless of the early burn quality. In contrast, for poor-burn cycles in Fig. $20 \& 21$ (summarized for Types C \& D in Fig. 24) the flame fails to propagate in the 6 o'clock direction. Instead, the flame tends to propagate upwards in the 12 o'clock direction. In this non-swirling flow, the flame propagation in the 12 o'clock direction is explained by the strong convection induced by the two spray plumes straddling the spark plug, as illustrated in Fig. 
24. Together these indicate that improper mixture distribution and turbulent flame quenching occur, from which the combustion may or may not recover.

With swirl, the images and PDFs in Fig. 18 (summarized for Type A in Fig. 24) in combination with PIV results shown in Figs. $11 \& 12$ indicate that some of the flame kernel propagates in the 12 o'clock direction, following the flow induced by the two spray plumes that straddle the spark plug. More importantly, the swirl flow consistently drives the bulk of the flame counterclockwise, quickly reaching the piston-bowl area located in the 6 o'clock direction. Flame propagation in multiple directions leads to high combustion stability throughout the combustion event, and allows the flame to reach all fuelcontaining regions before ongoing mixing produces overly lean zones where the flame may extinguish.

\section{Conclusions}

This study reveals, using PIV and flame imaging, both how in-cylinder swirl can stabilize combustion in a spray-guided stratified-charge DISI engine, and documents the mechanisms leading to poor combustion when operating without swirl. By combining optical diagnostics and pressure-based AHRR analysis, it is shown that the interaction of fuel sprays and intake-generated swirl flow creates a stronger and more repeatable vortex near the center of the piston bowl compared to the flow without the swirl. The redistribution of the gas-phase angular momentum by the liquid fuel spray creates a vortex that promotes effective and repeatable flame growth in multiple directions within the piston bowl. In contrast, operation without swirl displays unacceptable high COV of IMEP and cycle-to-cycle variability of flow field, spark-plasma direction, and flame-spread patterns, causing the appearance of partial-burn cycles at an elevated engine speed of $2000 \mathrm{rpm}$.

Due to the complexity of the in-cylinder flow and mixture fields, the exact reasons for flame-spread issues and flame quenching are still not completely understood. Nonetheless, one important result of this work is that operational limits, as defined by the appearance of partial-burn cycles, are not solely caused by cycle-to-cycle variability of the ignition or early flame-kernel growth. Combustion imaging revealed that cycles can experience extreme burning-rate regression and may or may not recover before the end of the cycle. The results of the early-phased combustion here suggest that the regression recovery process is not driven primarily by thermodynamics (increasing temperature) but rather is controlled by flow and/or mixing.

The pressure-based combustion analysis demonstrated that the performance of this particular engine and operating condition is consistent with the operation of other spray-guided stratified-charge engines using multi-hole direct injection of fuel. It follows that the conclusions, based on the physical processes measured here, are sufficiently fundamental to apply to other such engines. The value of this documentation is that it justifies investigation of the in-bowl flow, turbulence, and fuel-air mixing and their effect on the regression-recovery process.

\section{Acknowledgments}

The authors would like to thank Alberto Garcia, Gary Hubbard, Ken St. Hilaire, Keith Penney, and Sal Birtola for their dedicated support of the DISI laboratory. Also, thanks to Drs. W. Ethan Eagle and Kan Zha for helpful discussions and for reviewing this paper.

The work was performed at the Combustion Research Facility, Sandia National Laboratories, Livermore, CA. Financial support was provided by the U.S. Department of Energy, Office of Vehicle Technologies. 
Sandia National Laboratories is a multi-program laboratory managed and operated by Sandia Corporation, a wholly owned subsidiary of Lockheed Martin Corporation, for the U.S. Department of Energy's National Nuclear Security Administration under contract DE-AC04-94AL85000. Dr. Zongjie Hu's visit was financially supported by China Scholarship Council, and National Natural Science Foundation of China (Project NO. 51106113).

\section{References}

[1] C. Schwarz, E. Schünemann, B. Durst, J. Fischer, Potentials of the Spray-Guided BMW DI Combustion System, SAE Technical Paper 2006-01-1265 (2006)

[2] J. Smith, G. Szekely Jr, A. Solomon, S. Parrish, A Comparison of Spray-Guided Stratified-Charge Combustion Performance with Outwardly-Opening Piezo and Multi-Hole Solenoid Injectors, SAE Technical Paper 2011-01-1217 (2011)

[3] L. Schmidt, J. Seabrook, J. Stokes, M. Faizan, A. Zuhdi, S. Begg, M. Heikal, J. King, Multiple Injection Strategies for Improved Combustion Stability under Stratified Part Load Conditions in s Spray Guided Gasoline Direct Injection (SGDI) Engine, SAE Technical Paper 2011-01-1228 (2011)

[4] F. Altenschmidt, D. Bertsch, M. Bezner, The analysis of the ignition process on SI-engines with direct injection in stratified mode, 7th Intl Symp on Internal Combustion Diagnostics (2006) 395-411

[5] T.D. Fansler, D.L. Reuss, V. Sick, R. Dahms, Combustion Instability in Spray-Guided StratifiedCharge Engines - A Review, Int. J. Engine Res. 16 (2015) 260-305.

[6] B. Peterson, D.L. Reuss, V. Sick, On the Ignition and Flame Development in a Spray-Guided DirectInjection Spark-Ignition Engine, Combust. Flame. 161 (2014) 240-255.

[7] B. Peterson, D.L. Reuss, and V. Sick, High-speed Imaging Analysis of Misfires in a Spray-guided Direct Injection Engine, Proc. Combust. Inst. 33 (2011) 3089 - 3096.

[8] T.D. Fansler, M.C. Drake, B. Böhm, High-Speed Mie-Scattering Diagnostics for Spray-Guided Gasoline Engine Development, Proceedings of the $8^{\text {th }}$ International Symposium on Internal Combustion Diagnostics, (2008) 413-425.

[9] T.D. Fansler, B. Stojkovic, M.C. Drake, M.E. Rosalik, Local Fuel Concentration Measurements in Internal Combustion Engines using Spark-emission Spectroscopy, Applied Physics B, 75 (2002) 577-590. [10] T.D. Fansler, M.C. Drake, L. Düwel, F.P. Zimmermann, Fuel-spray and Spark Plug Interactions in Spray-guided Direct-injection Gasoline Engine, Proceedings of the Seventh International Symposium on Internal Combustion Diagnostics, (2006) 81-97.

[11] R.N. Dahms, M.C. Drake, T.D. Fansler, T.W. Kuo, N. Peters, Understanding ignition processes in spray-guided gasoline engines using high-speed imaging and the extended spark-ignition model SparkCIMM. Part A: Spark channel processes and the turbulent flame front propagation, Combust. Flame 158 (2011) 2229-2244.

[12] R.N. Dahms, T.D. Fansler, M.C. Drake, T.W. Kuo, A.M. Lippert, N. Peters, Modeling ignition phenomena in spray-guided spark-ignited engines, Proc. Combust. Inst., 32 (2009) 2743-2750

[13] W. Zeng, C. Idicheria, T. Fansler, M. Drake, Conditional Analysis of Enhanced Combustion Luminosity Imaging in a Spray- Guided Gasoline Engine with High Residual Fraction, SAE Technical Paper 2011-01-1281 (2011), doi: 10.4271/2011-01-1281.

[14] W. Zeng, M. Sjöberg, D.L. Reuss, Combined Effects of Flow/Spray Interactions and EGR on Combustion Variability for a Stratified DISI Engine, Proc. Combust. Inst. 35(2015) 2907-2914, http://dx.doi.org/10.1016/j.proci.2014.06.106 
[15] M. Sjöberg, W. Zeng, D. Reuss, Role of Engine Speed and In-cylinder Flow Field for Stratified and Well-mixed DISI Engine Combustion using E70, SAE Int. J. Engines 7 (2014) 642-655, doi:10.4271/2014-01-1241.

[16] W. Zeng, M. Sjöberg, D. Reuss, Using PIV Measurements to Determine the Role of the In-cylinder Flow Field for Stratified DISI Engine Combustion, SAE Int. J. Engines 7 (2014) 615-632, doi:10.4271/2014-01-1237.

[17] R. Stiehl, J. Schorr, C. Krüger, A. Dreizler, B. Böhm, Investigation of the Interaction of In-Cylinder Flow and Fuel Injection in an Optical Accessible Direct Injection Gasoline Engine, $25^{\text {th }}$ European Conference on Liquid Atomization and Spray Systems (2013)

[18] R. Stiehl, J. Schorr, C. Krüger, A. Dreizler, B. Böhm, In-Cylinder Flow and Fuel Spray Interactions in a Stratified Spray-Guided Gasoline Engine Investigated by High-Speed Laser Imaging Techniques, Flow Turbulence Combust. 91 (2013) 431-450.

[19] P. G. Hill, D. Zhang, the Effects of Swirl and Tumble on Combustion in Spark-Ignition Engines, Progress in Energy and Combustion Science, 20 (1994) 373-429.

[20] Zha, K., Busch, S., Park, C. and Miles, P. C., "A novel method for correction of temporally- and spatially-variant optical distortion in planar particle image velocimetry", submitted to Measurement Science and Technology (2016).

[21] Zha, K., Busch, S., Miles, P. C., Wijeyakulasuriya, S., Mitra, S. and Senecal, P. K., "Characterization of Flow Asymmetry During the Compression Stroke Using Swirl-Plane PIV in a Light-Duty Optical Diesel Engine with the Re-Entrant Piston Bowl Geometry" SAE Int. J. Engines 8 (2015) 1837-1855, doi: 10.4271/2015-01-1699.

[22] K. Lee, C. Bae, K. Kang, the Effects of Tumble and Swirl Flows on Flame Propagation in a FourValve S.I. Engine, Applied Thermal Engineering, 27 (2007) 2122-2130

[23] B. Petersen, and P. Miles, PIV Measurements in the Swirl-Plane of a Motored Light-Duty Diesel Engine, SAE Int. J. Engines 4(1):1623-1641, 2011, doi:10.4271/2011-01-1285.

[24] M.C. Drake, T.D. Fansler, A.M. Lippert, Stratified-charge combustion: modeling and imaging of a spray-guided direct-injection spark-ignition engine, Proc. Combust. Inst., 30 (2005) 2683-2691

[25] P.C. Miles, B.H. RempelEwert, R.D. Reitz, Squish-Swirl and Injection-Swirl Interaction in DirectInjection Diesel Engines, International Conference on Engines for Automobile (ICE) (2003) [26] P.C. Miles, Turbulent Flow Structure in Direct-Injection, Swirl-Supported Diesel Engines, Chapter 4, Flow and Combustion in Reciprocating Engines, Springer-Verlag Berlin Heidelberg, 2009, 173-256, doi: 10.1007/978-3-540-68901-0_4.

[27] W. Zeng, M. Sjöberg, D.L. Reuss, PIV Examination of Spray-Enhanced Swirl Flow for Combustion Stabilization in a Spray-Guided Stratified-Charge Direct-Injection Spark-Ignition Engine, Int. J. Engine Res. 16 (2015) 306-322, doi: 10.1177/1468087414564605

[28] J.B. Heywood, Internal Combustion Engine Fundamentals, McGraw-Hill, New York, 1988. [29] M. Sjöberg, W. Zeng, Combined Effects of Fuel and Dilution Type on Efficiency Gains of Lean Well-mixed DISI Engine Operation with Enhanced Ignition and Intake Heating, SAE Technical Paper 2016-01-0689 (2016).

[30] M. Sjöberg, D. Reuss, $\mathrm{NO}_{\mathrm{x}}$-Reduction by Injection-Timing Retard in a Stratified-Charge DISI Engine using Gasoline and E85, SAE Int. J. Fuels Lubr. 5 (2012)1096-1113.

[31] C. Fajardo, V. Sick, Flow Field Assessment in a Fired Spray-guided Spark-ignition Direct-injection Engine based on UV Particle Image Velocimetry with Sub Crank Angle Resolution, Proceedings of the combustion institute 31(2007) 3023-3031.

[32] R.J. Adrian, and J. Westerweel, Particle Image Velocimetry, Cambridge University Press, New York, 2010 
[33] P. Abraham, D. Reuss, V. Sick, High-Speed Particle Image Velocimetry Study of In-Cylinder Flows with Improved Dynamic Range, SAE Technical Paper 2013-01-0542 (2013)

[34] M. Megerle, V. Sick, D.L. Reuss, Measurement of Digital Particle Image Velocimetry Precision

using Electro-optically Created Particle-Image Displacements, Measurement Science and Technology 13 (2002) 997.

[35] J. G. Lee and D. A. Santavicca, Experimental Diagnostics for the Study of Combustion Instabilities in Lean Premixed Combustors, Journal of Propulsion and Power 19 (2003) 735-750.

[36] K. Kuwahara, H. Ando, Diagnostics of In-Cylinder Flow, Mixing and Combustion in Gasoline Engines, Measurement Science and Technology 11 (2000) 95-111

[37] Chen, H., Reuss, D.L., and Sick, V., “A Practical Guide for Using Proper Orthogonal Decomposition in Engine Research", International Journal of Engine Research 14(4) 307-319

[38] Chen, H., Reuss, D.L., and Sick, V., "On the Use and Interpretation of Proper Orthogonal

Decomposition of In-cylinder Engine Flows”, Measurement Science and Technology 23 (2012) 085302. 


\section{All Figure Captions}

Fig. 1. Illustration of the cross-section of the combustion chamber at TDC with a) piston, b) piston bowl, c) pistonbowl window, d) pent-roof window, e) spark plug, and f - injector, setup for PIV measurement with g) laser sheet location, h) high-speed camera, i) Bowditch-piston mirror, and j) camera view through piston-bowl window (the lower-right valve is deactivated to generate the swirl).

Fig. 2. Spectral response of blue, green and red for color camera (replotted based on Phantom v611 color camera sensor specification)

Fig. 3. Optical setup for simultaneous $\mathrm{OH}^{*}$ and natural flame luminosity imaging

Fig. 4. Comparison of (a) blue-pixel images to (b) $\mathrm{OH}^{*}$ images from five randomly selected individual cycles at $27^{\circ} \mathrm{CA}$ ATDC. Operating conditions correspond to Test 3 of Table 3.

Fig. 5. Probability maps of $\mathrm{OH}^{*}$ image and "blue" flame locations sampled over 100 cycles.

Fig. 6. Test averaged heat release and pressure analyses comparing steady-state metal-engine and skip-fired opticalengine operation. Occasional misfires have been excluded from these analyses

Fig. 7. Cycle-to-cycle variations of IMEPg for 1000 and $2000 \mathrm{rpm}$ with and without swirl (Tests 1-4 in Table 3), noting the standard deviation of IMEPg (STD), and combustion efficiency (CE).

Fig. 8. Correlation between IMEP $_{\mathrm{g}}$ and CA50 with FMFB at $2000 \mathrm{rpm}$, with and without swirl (Tests 3 and 4 in Table 3)

Fig. 9. AHRR analysis of early to late stages of combustion for 500 cycles in the continuously-fired metal engine $2000 \mathrm{rpm}$, with and without swirl

Fig. 10. Cycle-to-cycle variations of CA10 for 2000 rpm with and without swirl (Tests 3, 4 and 6 of Table 3); Cycle \# sorted from the smallest to largest of CA10.

Fig. 11. Ensemble mean flow, and spray at $2000 \mathrm{rpm}$ for operation with and without swirl SOIa $=-47^{\circ} \mathrm{CA}$, EOIa $=-$ $34^{\circ} \mathrm{CA}, \mathrm{ST}=-35^{\circ} \mathrm{CA}$ (Tests 3 and 4 in Table 4 ).

Fig. 12. Influence of swirl on cycle-to-cycle variations of the gas flow after injection and subsequent spark plasma motion. Three individual cycles selected from operation at $2000 \mathrm{rpm}$ with and without swirl $\left(\mathrm{SOIa}=-47^{\circ} \mathrm{CA}, \mathrm{ST}=-\right.$ $35^{\circ} \mathrm{CA}$, Tests 3 and 4 in Table 4).

Fig. 13. Ensemble average flow field and the corresponding RMS velocity fluctuation from the ensemble mean; vector fields and RMS images obtained during spark discharge and after injection for Tests 1-4 shown in Table 4. Fig. 14. Influence of intake-generated swirl and engine speed on changes of time-based CA10 deviation and spatial average of local RMS fluctuation from ensemble mean (Tests 1-4 in Table 4). The calculation of RMS is based on the region in the vicinity of the spark-plug as indicated in Fig. 13 with a dashed red rectangle. RMS data correspond to $-22^{\circ} \mathrm{CA}$ for $1000 \mathrm{rpm}$, and $-30^{\circ} \mathrm{CA}$ for $2000 \mathrm{rpm}$.

Fig. 15. Probability maps of spark plasma location for operation with and without swirl at $2000 \mathrm{rpm}$ (Tests 3 and 4 in Table 4)

Fig. 16. Correlations between early flame area and CA04 for operation with and without swirl at $2000 \mathrm{rpm}$ (Tests 3 and 4 in Table 2, optical operation for flame imaging). The flame imaging data at $-26^{\circ} \mathrm{CA}$ ATDC, correspond to MFB $\leq 1.5 \%$.

17. Cycle-to-cycle variations of CA10 and CA10 regions for different categories of flame propagation shown in Table 5 (flame imaging data)

Fig. 18. Type A (normal CA10, Normal FMBF, with swirl, 2000rpm) individual-cycle apparent heat-release analysis at $2000 \mathrm{rpm}$. Blue cycles highlight the range of cycles discussed in the text. The cycle highlighted in yellow corresponds to the single-cycle images (top row). The lower row is the flame probability map for the 10 blue highlighted cycles.

Fig. 19. Individual-cycle apparent heat-release analysis for $2000 \mathrm{rpm}$ without swirl. Blue cycles highlight the Type B cycles, normal CA10, normal FMFB. The cycle highlighted in yellow corresponds to the single-cycle images (top row). The lower row is the flame probability map for the 10 Type B (blue) cycles.

Fig. 20. Individual-cycle apparent heat-release analysis for $2000 \mathrm{rpm}$ without swirl. Blue cycles highlight the Type $\mathrm{C}$ cycles, normal CA10, poor FMFB. The cycle highlighted in yellow corresponds to the single-cycle images (top row). The lower row is the flame probability map for the 7 Type $\mathrm{C}$ (blue) cycles. 
Fig. 21. Type D individual-cycle apparent heat-release analysis for $2000 \mathrm{rpm}$ without swirl. Blue cycles highlight the Type D cycles, poor CA10, poor FMFB. The cycle highlighted in yellow corresponds to the single-cycle images (top row). The lower row is the flame probability map for the 7Tupe D (blue) cycles.

Fig. 22. Individual-cycle apparent heat-release analysis for $2000 \mathrm{rpm}$ without swirl. Blue cycles highlight the Type E cycles, poor CA10, normal FMFB. The cycle highlighted in yellow corresponds to the single-cycle images (top row). The lower row is the flame probability map for the 7 Type $\mathrm{E}$ (blue) cycles.

Fig. 23. AHRR curves of the selected individual cycles shown in Figs. 18 to 22 (yellow curves)

Fig. 24. Conceptual model of flame propagation with and without swirl 